\title{
Será a interface sintaxe-discurso necessariamente um locus de opcionalidade em L2? O caso da inversão locativa em inglês $L 2^{1}$
}

\author{
Joana Teixeira \\ CLUNL / FCSH - Universidade NOVA de Lisboa
}

\begin{abstract}
:
This study investigates the acquisition of locative inversion in L1 European Portuguese (EP) - L2 English and L1 French - L2 English. Its purpose is to test two opposing hypotheses on the end-state of L2 acquisition at the syntaxdiscourse interface: the Interface Hypothesis (IH) and the L1+input Hypothesis (LIH). The former proposes that the syntax-discourse/pragmatics interface is a locus of residual, but permanent, optionality, because L2 speakers are less than optimally efficient at integrating syntactic and contextual information in real-time language use as a by-product of bilingualism. The latter, in contrast, sustains that structures at this interface generate problems at highly advanced levels of proficiency iff their properties are different in the L1 and the L2 and the evidence available in the input is not transparent (e.g., because the structure is rare). By administering 2 untimed drag and drop tasks, 2 speeded acceptability judgement tasks and 1 syntactic priming task to a total of 80 participants, we tested, on the one hand, the type of intransitive verb allowed in locative inversion and, on the other, the type of discourse context in which this inversion is admitted. The results disconfirm the LIH and confirm (most of) the IH's predictions.
\end{abstract}

Keywords: second language acquisition, end-state, syntax-discourse interface, locative inversion.

Palavras-chave: aquisição de segunda língua, estado final, interface sintaxe-discurso, inversão locativa.

\section{Introdução}

Ao longo da última década, tem sido sugerido em vários estudos que as propriedades que envolvem a interface entre sintaxe e domínios externos à gramática, como discurso, são das mais problemáticas para falantes de segunda língua (L2), podendo gerar dificuldades até mesmo

\footnotetext{
${ }^{1}$ A investigação conducente a este artigo foi desenvolvida na Universidade de Edimburgo e na Universidade Nova de Lisboa, no âmbito do projeto de doutoramento "L2 acquisition at the interfaces: Subject-verb inversion in L2 English and its pedagogical implications", financiado pela Fundação para a Ciência e a Tecnologia (ref. ${ }^{a}$ PD/BD/52263/2013). Agradeço a Ana Madeira e a Antonella Sorace pelas suas úteis sugestões e comentários durante as fases de preparação e execução do estudo experimental apresentado neste artigo. Agradeço também a John-Sebastian Schütter pela ajuda no desenho da tarefa de priming sintático e aos revisores anónimos deste volume pelos seus comentários a uma versão anterior do presente artigo. Por fim, queria expressar o meu agradecimento a todos os falantes nativos de francês, inglês e português europeu que participaram nas tarefas experimentais sobre inversão locativa em inglês.
} 
no nível de proficiência mais avançado que estes conseguem atingir - o nível quase nativo (e.g. Belletti, Bennati, \& Sorace, 2007; Sorace, 2003, 2011, 2016; Sorace \& Filiaci, 2006; Tsimpli \& Sorace, 2006; Wilson, Sorace, \& Keller, 2009; entre outros). Embora seja amplamente reconhecido que a interface sintaxe-discurso é potencialmente problemática na aquisição de L2 (cf. White, 2009, 2011), três questões-chave continuam a suscitar debate na literatura: (i) Será esta interface necessariamente uma área de divergência no estádio final de aquisição de L2? (ii) Serão os problemas nesta interface de natureza representacional ou de processamento? (iii) Que fator ou combinação de fatores está na origem destes problemas (e.g., a influência da língua materna (L1), o input e/ou o modo como a experiência bilingue afeta o processamento)? Com vista a lançar nova luz sobre estas questões, o presente trabalho investiga a aquisição de inversão locativa (1) - uma construção na interface sintaxe-discurso ainda pouco estudada por falantes avançados e quase nativos de inglês L2-francês L1 e inglês L2-português europeu (PE) L1.

[In the forest] [lived] [a family of bears]

$$
\text { Loc(ativo) V(erbo) S(ujeito) }
$$

Este trabalho está organizado do seguinte modo: a secção 2 sintetiza as duas hipóteses atualmente existentes na literatura sobre o estádio final de aquisição de L2 na interface sintaxediscurso - a Hipótese de Interface (Sorace \& Filiaci, 2006; Sorace, 2011) e uma recente hipótese, que surgiu em trabalhos de Slabakova (2015) e Domínguez e Arche (2014), a que nos referiremos como "Hipótese L1 + input" por facilidade de exposição. Na secção 3, explicamos por que motivos a aquisição de estruturas de inversão locativa em inglês L2 é um terreno de teste apropriado para estas hipóteses e descrevemos as propriedades sintático-discursivas deste tipo de inversão em inglês, francês e PE. A secção 4 apresenta as questões de investigação, predições e metodologia deste estudo. Nas secções 5 e 6 , são descritos e discutidos os seus resultados. Por fim, a secção 7 apresenta as conclusões deste estudo sobre o estádio final de aquisição de L2 na interface sintaxe-discurso. 


\section{Hipóteses sobre o estádio final de aquisição de L2 na interface sintaxe-discurso}

A investigação desenvolvida em aquisição de L2 sobre interfaces linguísticas tem sido muito influenciada por uma hipótese formulada por Sorace e Filiaci (2006) para explicarem os padrões de comportamento encontrados em estádios altamente avançados de aquisição - a Hipótese de Interface (HI). De acordo com esta hipótese, enquanto propriedades estritamente sintáticas são completamente adquiríveis numa L2, as que envolvem a interface entre sintaxe e domínios externos à gramática, como discurso e pragmática, são uma área de opcionalidade residual $^{2}$, mas permanente, no estádio final de aquisição. Na sua forma atual, a HI propõe que esta opcionalidade é fruto de ineficiências na integração de informação sintática com informação pragmático-discursiva no uso da língua em tempo real, as quais, por sua vez, são um efeito secundário do bilinguismo ${ }^{3}$ (Sorace, 2011, 2016). Mais especificamente, tem sido defendido em trabalhos recentes (cf. Sorace, 2016 e referências aí citadas) que a experiência bilingue, por envolver a constante inibição de uma língua enquanto outra está a ser usada, confere vantagens ao nível do controlo inibitório, mas potenciais desvantagens na capacidade de integração / updating, que exige disengagement de inibição e que poderá, por isso, participar numa relação de trade-off com a capacidade de controlo inibitório. De acordo com esta hipótese, há mais ineficiências de integração na produção/interpretação de estruturas que envolvem a interface sintaxe-discurso/pragmática do que de estruturas que envolvem interfaces internas à gramática (e.g. sintaxe-semântica), porque a integração de informação sintática com informação proveniente de domínios externos requer mais recursos cognitivos do que a integração de informação com origem em diferentes módulos dentro da gramática.

A evidência que apoia a HI vem predominantemente de estudos sobre a aquisição de inversão "livre" e de sujeitos pronominais nulos e plenos em línguas de sujeito nulo consistente, como o italiano, o espanhol e o PE. Estes estudos têm mostrado, de modo sistemático, que os falantes avançados e quase nativos destas línguas têm uma gramática de sujeito nulo, mas exibem dificuldades permanentes relativamente às condições discursivas que determinam a distribuição de ordens SV e VS e de sujeitos pronominais plenos. É, assim, na interface sintaxe-

\footnotetext{
${ }^{2}$ Segundo Sorace (2003: 140), a opcionalidade residual é um fenómento característico do estádio quase nativo de aquisição de L2, em que "a steady state is reached in which the target option is strongly but not categorically preferred and the nontarget option surfaces in some circumstances".

${ }^{3}$ Salvo indicação em contrário, o termo "bilingue" é usado neste artigo no sentido lato de falante com proficiência em duas ou mais línguas.
} 
discurso que se situam os seus problemas. Este padrão de comportamento é encontrado não só em pares de línguas em que a L1 é uma língua de sujeito obrigatório e a L2 uma língua de sujeito nulo (e.g. inglês L1 - italiano L2, inglês L1 - espanhol L2 ou alemão L1 - PE L2, como em Belletti et al., 2007; Cristóbal Lozano, 2003, 2006b; Madeira, Xavier, \& Crispim, 2009; Sorace \& Filiaci, 2006), como também em combinações em que a L1 e a L2 são línguas de sujeito nulo consistente (e.g. italiano L1 - espanhol L2, grego L1 - espanhol L2 ou espanhol L1 - PE L2, como em Bini, 1993; Cristóbal Lozano, 2006a; Margaza \& Bel, 2006; Mendes \& Iribarren, 2007), o que sugere que estas dificuldades na interface sintaxe-discurso não resultam (pelo menos exclusivamente) da influência da L1 sobre a L2. Além de gerarem dificuldades permanentes a falantes de L2, as propriedades sintático-discursivas dos sujeitos em línguas de sujeito nulo são problemáticas para outras populações bilingues, como crianças bilingues simultâneas (cf. Sorace, Serratrice, Filiaci, \& Baldo, 2009) e adultos que estão numa situação de erosão linguística devido a exposição prolongada a uma L2 (cf. Chamorro, Sorace, \& Sturt, 2016; Tsimpli, Sorace, Heycock, \& Filiaci, 2004). Em conjunto, estes factos têm sido tomados pelas proponentes da $\mathrm{HI}$ como evidência robusta de que a interface sintaxe-discurso é necessariamente problemática para falantes bilingues, em geral, e falantes de L2, em particular, por ineficiências de processamento relacionadas com a experiência bilingue.

Os trabalhos que se têm debruçado sobre outras propriedades na interface sintaxediscurso têm, contudo, produzido resultados menos claros quanto à validade desta hipótese. De facto, embora a HI seja confirmada por vários estudos sobre propriedades sintático-discursivas que não estão relacionadas com o parâmetro do sujeito nulo (e.g. Bohnacker \& Rosén, 2007; Hopp, 2004; Wilson, 2009; Wilson et al., 2009), nos últimos anos, têm surgido alguns trabalhos que não estão em linha com as suas predições, uma vez que mostram que falantes avançados e/ou quase nativos têm um desempenho convergente com a L2 em relação a estruturas na interface sintaxe-discurso, como deslocação à esquerda e à direita em francês L2 (Donaldson, 2011a, 2011b), redobro de clítico em búlgaro L2 (Ivanov, 2009, 2012) e anteposição de foco (focus fronting), deslocação à esquerda clítica e deslocação à direita clítica em espanhol L2 (Domínguez \& Arche, 2014; Slabakova, 2015; Slabakova, Kempchinsky, \& Rothman, 2012; Slabakova, Rothman, \& Kempchinsky, 2011; Slabakova, Rothman, Leal Mendez, Campos, \& Kempchinsky, 2011). A HI não reúne, por isso, consenso na literatura. 
Recentemente, tem vindo a ganhar terreno uma hipótese alternativa, que designamos por "Hipótese L1+input" (HLI). Esta tem origem no trabalho de Slabakova (2015) sobre aquisição de deslocações à esquerda por falantes avançados e quase nativos de inglês L1 espanhol L2 e espanhol L1 - inglês L2. Através de uma série de tarefas de juízos de aceitabilidade, neste trabalho, Slabakova testa, por um lado, estruturas de anteposição de foco (2), que têm as mesmas propriedades em inglês e espanhol, e, por outro, estruturas de deslocação à esquerda clítica em espanhol (3) e de topicalização em inglês (4), que têm a mesma função discursiva, mas diferentes propriedades sintáticas e diferente frequência no input. As últimas são significativamente menos frequentes do que as primeiras.

(2) [Contexto: O João comprou os móveis.]

a. LA ALFOMBRA compró (no los muebles).

b. THE RUG he bought (not the furniture).

(3) [Contexto: Preciso de comprar o jornal e pão.]

El periódico, lo compraré antes de ir al trabajo.

(4) [Contexto: Preciso de comprar o jornal e pão.]

The newspaper, I will buy (*it) before work.

(adaptado de Slabakova, 2015: 675)

Ao contrário do que a HI prediria, a maioria destas construções na interface sintaxediscurso parecem não ser problemáticas para os falantes de L2. Os falantes de inglês L1 espanhol L2 adquirem com sucesso quer as estruturas de anteposição de foco, quer as de deslocação à esquerda clítica. Já os falantes de espanhol L1 - inglês L2 conseguem adquirir as estruturas de anteposição de foco, mas não as de topicalização. Estes falantes aceitam topicalizações agramaticais em inglês, como "the newspaper, I will buy it before work", mesmo em níveis quase nativos. Para explicar estes resultados, Slabakova (2015) propõe (contra a HI) que as estruturas na interface sintaxe-discurso só geram problemas em níveis altamente avançados quando (i) têm propriedades diferentes na L1 e na L2 e (ii) são raras no input. Complementando esta proposta, Domínguez e Arche (2014) mostram que não é apenas a 
frequência da construção alvo que é um fator relevante. De um modo mais geral, a falta de transparência da evidência disponível no input pode levar a que os falantes de L2 nunca eliminem propriedades transferidas da L1 para a L2. Em síntese, segundo as proponentes da HLI, é uma combinação de fatores relacionados com a L1 e o input que determina se uma dada estrutura na interface sintaxe-discurso gerará ou não problemas no estádio final de aquisição de L2, os quais poderão ser de natureza sintática, contrariamente ao que a HI prediz.

Crucialmente, quer os estudos em que se apoia a HLI, quer a maioria dos restantes estudos que (aparentemente) infirmam a HI baseiam-se em tarefas offline e sem restrições de tempo, em particular tarefas de juízos de aceitabilidade, que, como defendido por Sorace (2011), não são as mais adequadas para captar o tipo de opcionalidade predito pela HI, uma vez que dão aos participantes tempo ilimitado para monitorizarem as suas respostas e acederem ao seu conhecimento (meta)linguístico. Note-se que, ao contrário do que é, por vezes, assumido em trabalhos sobre interfaces linguísticas, a versão atual da HI não prediz que as estruturas na interface sintaxe-discurso são impossíveis de adquirir. Esta hipótese prediz antes que, mesmo não havendo qualquer problema representacional, ineficiências de processamento relacionadas com a condição bilingue originarão opcionalidade no desempenho dos falantes de L2. Assim, tal como Sorace (2011) nota, o tipo de opcionalidade predito pela HI poderá apenas ser captável por tarefas experimentais que forneçam informação sobre questões de processamento, como tarefas online (e.g., eyetracking ou self-paced reading) ou tarefas offline que coloquem um peso extra sobre os recursos de processamento do falante, por exemplo, sob a forma de pressão de tempo (e.g., tarefa de juízos de aceitabilidade rápidos) e/ou de uma tarefa concorrente (e.g., digit recall task). À luz destas clarificações sobre a HI, pode concluir-se que as tarefas offline e sem pressão de tempo que mostram que falantes altamente avançados convergem totalmente com a L2 na aquisição de estruturas na interface sintaxe-discurso não colocam em causa as predições desta hipótese. Só aquelas que revelam problemas sintáticos neste tipo de estruturas em níveis quase nativos são, de facto, problemáticas para a HI.

Em suma, atualmente, existem duas hipóteses opostas sobre o estádio final de aquisição de L2 na interface sintaxe-discurso: a HI e a HLI. Devido aos problemas metodológicos que acabámos de apontar, é difícil chegarmos a conclusões firmes sobre a validade destas hipóteses com base na evidência atualmente disponível na literatura. Por este motivo, é necessária mais investigação sobre a interface sintaxe-discurso em L2. 


\section{Inversão locativa em inglês, francês e português europeu}

Com o objetivo de testar a HI e a HLI, o presente trabalho investiga a aquisição de inversão locativa, i.e., da ordem LocVS, em inglês L2 - francês L1 e inglês L2 - PE L1. Este é um terreno apropriado para testar as duas hipóteses pelos seguintes motivos: primeiro, porque a inversão locativa do inglês é uma estrutura que envolve a interface entre sintaxe e discurso; segundo, porque é infrequente no input e raramente ensinada em cursos de inglês; e, por último, porque, como será mostrado na presente secção, a inversão locativa está sujeita a restrições semelhantes em inglês e francês, mas não em PE.

Em inglês, a inversão locativa tem como função apresentar um referente novo no cenário espácio-temporal definido pelo constituinte anteposto (Birner, 1994, 1996; Birner \& Ward, 1998; Bresnan, 1994; Ward, Birner, \& Huddleston, 2002). Por este motivo, apenas é discursivamente adequada quando o sujeito é (parte do) foco (cf. Bresnan, 1994; Cornish, 2005; Culicover \& Winkler, 2008; Levin \& Rappaport Hovav, 1995, entre muitos outros) e o XP préverbal é um tópico cénico, i.e., um constituinte pressuposto que define uma localização espáciotemporal (Teixeira, 2016b, 2016c), tal como ilustrado em (5).

\section{a. Locativo pressuposto + Sujeito foco}

They have a great big tank in the kitchen, and in the tank are sitting a whole bunch of pots. (Ward, Birner \& Huddleston, 2002: 1386)

\section{b. Locativo foco + Sujeito pressuposto}

They have a whole bunch of pots in the kitchen, and ??in a great big tank are sitting all of the pots. (Ward, Birner \& Huddleston, 2002: 1386)

\section{c. Locativo pressuposto + Sujeito pressuposto}

What does the Mexican president do in the slum? ??In the slum lives the Mexican president.

\section{d. Locativo foco + Sujeito foco}

Did you hear the weird report on the evening news? ??In a slum lives an American billionaire.

A inversão locativa do inglês comporta-se de modo distinto de acordo com o peso estrutural do sujeito. Quando o sujeito é pesado, este tipo de inversão é permitido com todas as 
classes de verbos intransitivos $^{4}$ (6) (Culicover \& Levine, 2001; Rizzi \& Shlonsky, 2006). Em contraste, nos casos em que o sujeito é leve, apenas admitem inversão locativa verbos inacusativos ${ }^{5}$, como appear ('aparecer') ou emerge ('surgir') (7), e verbos inergativos ${ }^{6}$ que expressem uma atividade prototípica do referente do sujeito, como o inergativo wave ('abanar, acenar') quando acompanhado de um sujeito que prototipicamente abana como a banner ('uma bandeira'), em (8a) (Culicover \& Levine, 2001; Levin \& Rappaport Hovav, 1995; Rizzi \& Shlonsky, 2006). Crucialmente, estes últimos verbos, a que chamaremos "inergativos redundantes" por facilidade de exposição, parecem comportar-se semântica e sintaticamente mais como inacusativos do que como verdadeiros inergativos (para mais detalhes, cf. Mendikoetxea, 2006).

(6) In the room appeared / slept the students who had heard about the social psych experiment that we were about to perpetrate.

(baseado em Culicover \& Levine, 2001: 293)

(7) In the room appeared / ??slept John.

(8) a. From the flagpole waved a tattered banner.

(Levin \& Rappaport Hovav, 1995: 259)

b. ??From the roof waved a bearded student.

(Levin \& Rappaport Hovav, 1995: 259)

As diferenças existentes entre inversão locativa leve e pesada são fruto do facto de estas duas estruturas serem derivadas de forma distinta. De acordo com as análises de Culicover e Levine (2001) e Rizzi e Shlonsky (2006), nas estruturas de inversão locativa pesada, o sujeito move-se do VP para a posição canónica de sujeito e depois para uma posição adjunta ao IP, através de heavy-NP shift. Por isso, este tipo de inversão é compatível quer com verbos que selecionam um argumento interno, i.e., verbos inacusativos, quer com verbos com um

\footnotetext{
${ }^{4}$ Note-se que aqui a noção de "intransitivo" inclui verbos na forma passiva.

${ }^{5}$ Verbos cujo único argumento é gerado em posição de objeto e tem o papel de temático de tema ou de paciente.

${ }^{6}$ Verbos cujo único argumento é gerado em Spec, VP e, tipicamente, tem o papel de temático de agente.
} 
argumento externo, i.e., verbos inergativos. Nas estruturas de inversão locativa leve, pelo contrário, o sujeito é gerado na posição de complemento do VP e permanece in situ, o que leva a que este tipo de inversão só seja compatível com verbos que selecionam um argumento interno. É sobre a inversão locativa leve, considerada por muitos autores a "verdadeira" inversão locativa (e.g., Culicover \& Levine, 2001), que se debruça o presente trabalho. Por isso, doravante sempre que usarmos o termo "inversão locativa", estaremos a referir-nos a inversão locativa leve.

Além de estar sujeita às restrições sintáticas descritas acima, a distribuição dos verbos em inversão locativa é condicionada por fatores discursivos. Para ser admitido, o verbo tem de ser compatível com a função apresentacional deste tipo de inversão e não pode ser pragmaticamente noteworthy em relação ao sujeito, que é o constituinte ao qual a ordem locativo - verbo - sujeito dá destaque (cf. Birner, 1996; Birner \& Ward, 1998; Holler \& Hartmann, 2012; Levin \& Rappaport Hovav, 1995; Ward et al., 2002). Em poucas palavras, o verbo tem de ser informacionalmente leve. Estas condições são satisfeitas pelos verbos inacusativos de existência e aparecimento (e.g. arrive 'chegar', come 'vir', appear 'aparecer' para uma lista completa, cf. Levin, 1993), que intrinsecamente têm uma função apresentacional e são informacionalmente leves, e pelos verbos inergativos redundantes, que, por expressarem uma ação prototípica do sujeito, estão reduzidos a uma função essencialmente apresentacional / existencial. Prova disto é o facto de, numa frase como (9), o verbo swim ('nadar') poder ser substituído pelo verbo be ('ser/estar') sem que isso acarrete qualquer mudança de significado substancial. Ao contrário destes verbos, os inacusativos de mudança de estado (e.g., melt 'derreter', break 'partir'- para uma lista completa, cf. Levin, 1993) são, geralmente, incompatíveis com a função apresentacional da inversão locativa, pois aquilo que derrete ou se parte desaparece e, portanto, não pode ser introduzido no cenário espácio-temporal definido pelo XP anteposto. Por este motivo, esta subclasse de inacusativos tende a ser rejeitada neste tipo de inversão (10a) (cf. Holler \& Hartmann, 2012; Levin \& Rappaport Hovav, 1995). Apenas é aceite quando encaixada em contextos relativamente raros em que o sujeito é apresentável na localização definida pelo XP anteposto, apesar de o verbo manter o seu sentido de mudança de estado (cf. Holler \& Hartmann, 2012). Este é o caso do contexto (10b), em que a inserção do advérbio slowly ('lentamente') torna o sujeito, an iceberg ('um iceberg'), apresentável no cenário das ruas de Chicago. 
(9) Around the plants swam many colourful fish = around the plants were many colourful fish.

(10) a. ??In the kitchen broke a glass.

b. ??On the streets of Chicago melted a lot of snow.

c. On the streets of Chicago slowly melted an iceberg.

Consideremos, por fim, as propriedades da inversão locativa em francês e PE. No que diz respeito ao XP anteposto e ao sujeito, as duas línguas comportam-se como o inglês, uma vez que requerem que o XP tenha o estatuto de tópico cénico e que o sujeito pós-verbal seja (parte do) foco (Cornish, 2001, 2005; Lahousse, 2003, 2011; Teixeira, 2016b; entre outros), tal como ilustram os exemplos em (11).

(11) a. Locativo pressuposto + Sujeito foco

i. Marie possède une table basse en marbre. Sur la table se trouve un vase de cristal.

ii. A Maria tem uma mesa de jantar em mármore. Em cima da mesa está uma jarra de cristal.

\section{b. Locativo foco + Sujeito pressuposto}

i. Marie possède un grand vase de cristal. ??Sur la/une table se trouve le vase (de cristal).

ii. A Maria tem uma grande jarra de cristal. ??Em cima da/ de uma mesa está a jarra (de cristal).

\section{c. Locativo pressuposto + Sujeito pressuposto}

i. Qu'est-ce que fait l'ex-président péruvien dans le bidonville? ??Dans le bidonville habite l'ex-président péruvien.

ii. O que faz o ex-presidente peruano no bairro de lata? ??No bairro de lata vive o ex-presidente peruano. 


\section{d. Locativo foco + Sujeito foco}

i. Jean, as-tu lu les faits divers? ??Dans un bidonville habite un ex-président péruvien.

ii. João, leste isto? ??Num bairro de lata vive um ex-presidente peruano.

Já no que concerne a distribuição dos verbos, apenas o francês tem um comportamento semelhante ao do inglês. Tal como esta língua, o francês permite inversão locativa com verbos inacusativos de existência e aparecimento (12a) e inergativos redundantes (12b), mas não com inacusativos de mudança de estado (12c) e inergativos não redundantes (12d). Ao contrário do inglês e do francês, o PE permite inversão locativa com todos os tipos de verbos intransitivos (13), independentemente de estes serem ou não informacionalmente leves e de serem ou não acompanhados de sujeitos pesados (Pereira, 1998).
a. Dans cette région du monde sont apparus les premiers hommes. ${ }^{7}$
b. Dans l'aquarium nageaient des poissons colorés.
c. ??Dans la cuisine s'est brisé un verre.
d. ??À côté de notre table a vomi un garçon.
a. Nesta região do mundo apareceram os primeiros homens.
b. No aquário nadavam peixes coloridos.
c. Na cozinha partiu-se um copo.
d. Junto à nossa mesa vomitou um rapaz.

Em síntese, enquanto o francês se comporta como o inglês em todos os aspetos, o PE só se assemelha a esta língua no que diz respeito aos tipos de contextos discursivos compatíveis com inversão locativa. A distribuição de verbos nesta construção está sujeita a diferentes restrições em PE e inglês.

\footnotetext{
${ }^{7}$ Os exemplos em (13) são tradução das frases em (12). 


\section{O presente estudo}

\subsection{Questões de investigação e predições}

À luz do atual estado da arte, sintetizado na secção 2, e tendo em conta as características da inversão locativa em inglês, francês e PE, descritas na secção 3, formulámos as seguintes questões de investigação:

1. Será que os falantes quase nativos e avançados de inglês exibem problemas quanto a propriedades da inversão locativa ${ }^{8}$ que envolvem a interface entre sintaxe e discurso, nomeadamente (i) as condições sintático-discursivas que governam a distribuição de verbos com características inacusativas e (ii) as condições discursivas que determinam se o sujeito pode ocorrer em posição pós-verbal e o locativo em posição pré-verbal?

2. Será que os falantes quase nativos e/ou avançados de inglês exibem problemas relativamente a uma propriedade sintática como a agramaticalidade de verdadeiros verbos inergativos em inversão locativa?

3. Se os falantes quase nativos e/ou avançados exibirem problemas na aquisição de inversão locativa, serão eles um efeito do processamento bilingue e/ou de outros fatores, como a influência da L1?

A HI e a HLI fazem predições diferentes em relação a estas questões, tal como mostra a seguinte tabela:

\footnotetext{
${ }^{8}$ Como explicitado na secção 3, o presente trabalho tem como foco a inversão locativa leve. Por isso, sempre que usamos aqui o termo "inversão locativa", estamos a referir-nos a inversão locativa com sujeitos estruturalmente leves.
} 


\begin{tabular}{|c|c|c|}
\hline $\begin{array}{l}\text { Questão de } \\
\text { investigação }\end{array}$ & Predições da HI & Predições da HLI \\
\hline 1 & $\begin{array}{l}\text { Os falantes portugueses e franceses de inglês } \\
\text { exibirão opcionalidade relativamente a } \\
\text { propriedades na interface sintaxe-discurso } \\
\text { nos níveis avançado e quase nativo, mas esta } \\
\text { poderá apenas ser visível em tarefas } \\
\text { exigentes em termos de processamento. }\end{array}$ & $\begin{array}{l}\text { Os falantes franceses de inglês num nível quase nativo } \\
\text { convergirão com a } L 2 \text {, mas os falantes portugueses com } \\
\text { nível avançado e quase nativo em inglês exibirão } \\
\text { divergência relativamente às propriedades da inversão } \\
\text { locativa que são diferentes na sua L1 e na L2, i.e., as } \\
\text { condições que determinam a distribuição dos verbos } \\
\text { neste tipo de inversão. }\end{array}$ \\
\hline 2 & $\begin{array}{l}\text { Os falantes quase nativos de inglês não terão } \\
\text { problemas de natureza sintática, } \\
\text { independentemente de a L1 ser ou não } \\
\text { semelhante à L2. Não é, contudo, de excluir } \\
\text { a possibilidade de os falantes em nível } \\
\text { avançado (mas nunca quase nativo) terem } \\
\text { problemas deste tipo. }\end{array}$ & $\begin{array}{l}\text { Os falantes franceses de inglês num nível quase nativo } \\
\text { terão um comportamento alvo, mas os falantes } \\
\text { portugueses nos níveis avançado e quase nativo } \\
\text { aceitarão inversão locativa com verbos inergativos não } \\
\text { redundantes, porque estes são admitidos na sua L1 e a } \\
\text { inversão locativa é uma estrutura pouco frequente em } \\
\text { inglês. }\end{array}$ \\
\hline 3 & $\begin{array}{l}\text { Os problemas dos falantes quase nativos } \\
\text { serão um efeito de ineficiências de } \\
\text { processamento associadas ao bilinguismo e, } \\
\text { por isso, ocorrerão independentemente de a } \\
\text { L1 ser ou não diferente da L2. É possível que } \\
\text { os problemas dos falantes avançados tenham } \\
\text { a mesma fonte. }\end{array}$ & $\begin{array}{l}\text { Os problemas dos falantes avançados e quase nativos } \\
\text { com respeito a este tipo infrequente de inversão serão } \\
\text { causados pela influência da L1 sobre as suas } \\
\text { representações da L2. }\end{array}$ \\
\hline
\end{tabular}

Tabela 1: Predições da HI e da HLI sobre as questões de investigação do presente trabalho

\subsection{Participantes}

Participaram neste estudo 26 falantes monolingues de inglês, 26 falantes de inglês L2francês L1 e 28 falantes de inglês L2-PE L1. Os falantes nativos de inglês eram estudantes universitários, com idades compreendidas entre os 18 e os 52 anos, que viviam, à data do estudo, na Escócia e não tinham proficiência avançada em qualquer outra língua, apesar de terem recebido instrução em, pelo menos, uma L2 durante o seu percurso escolar. Os falantes nativos de PE e de francês eram estudantes universitários que começaram a ser expostos ao inglês em contexto escolar entre os 8 e os 13 anos, mas só passaram a ter uma exposição mais intensa a esta língua na adolescência. Tendo em conta estes factos, e assumindo com Meisel (2008: 59) que os indivíduos que começam a ter exposição a uma L2 numa idade igual ou superior a 8 anos são aprendentes "adultos", consideramos que todos os falantes não nativos de inglês que participaram no presente estudo podem ser classificados como aprendentes adultos de L2. Estes falantes foram divididos em quatro grupos: (i) grupo de franceses com nível avançado em inglês 
( $n=15)$, (ii) grupo de franceses com nível quase nativo em inglês $(n=11)$, (iii) grupo de portugueses com nível avançado em inglês $(n=17)$ e (iv) grupo de portugueses com nível quase nativo em inglês $(n=11)$. Os detalhes sobre o perfil sociolinguístico de cada grupo são apresentados na tabela 2 .

\begin{tabular}{|c|c|c|c|c|c|c|c|c|}
\hline \multirow{2}{*}{ Grupo } & \multicolumn{2}{|c|}{ Idade } & \multicolumn{2}{|c|}{$\begin{array}{c}\text { Idade de início de } \\
\text { exposição regular ao } \\
\text { inglês }\end{array}$} & \multicolumn{2}{|c|}{$\begin{array}{c}\text { Anos de } \\
\text { aprendizagem do } \\
\text { inglês }\end{array}$} & \multicolumn{2}{|c|}{$\begin{array}{l}\text { Anos de residência } \\
\text { em países anglófonos }\end{array}$} \\
\hline & Média & $\begin{array}{l}\text { Desvio } \\
\text { padrão }\end{array}$ & Média & $\begin{array}{l}\text { Desvio } \\
\text { padrão }\end{array}$ & Média & $\begin{array}{l}\text { Desvio } \\
\text { padrão }\end{array}$ & Média & $\begin{array}{l}\text { Desvio } \\
\text { padrão }\end{array}$ \\
\hline \multicolumn{9}{|l|}{$\begin{array}{l}\text { PE L1 - } \\
\text { inglês L2 }\end{array}$} \\
\hline Quase nativos & 31,09 & 9,23 & 9,09 & 1,08 & 12,64 & 3,42 & 3,47 & 4,85 \\
\hline Avançados & 24,88 & 8,86 & 8,94 & 1,26 & 10,06 & 2,44 & 0,60 & 0,89 \\
\hline \multicolumn{9}{|l|}{$\begin{array}{l}\text { Francês L1 - } \\
\text { inglês L2 }\end{array}$} \\
\hline Quase nativos & 21,73 & 2,60 & 11,09 & 1,38 & 8,36 & 2,67 & 3,73 & 3,29 \\
\hline Avançados & 21,00 & 1,59 & 9,33 & 1,66 & 11,27 & 2,05 & 0,93 & 0,39 \\
\hline
\end{tabular}

Tabela 2: Dados biográficos sobre os falantes de inglês L2

O nível de proficiência dos falantes não nativos de inglês foi avaliado através de uma versão adaptada do procedimento de seleção usado por Sorace e Filiaci (2006), que foi originalmente desenhado por White e Genesee (1996). No âmbito desta avaliação, todos os participantes foram entrevistados individualmente em inglês durante cerca de 10 minutos. $\mathrm{Na}$ entrevista, foram usados cartoons para induzir produção espontânea sobre um leque variado de tópicos. Uma amostra da produção de cada participante (com cerca de 2 minutos) foi, subsequentemente, selecionada, de modo aleatório, e avaliada por três falantes monolingues de inglês (britânico) com algum treino em linguística, tendo em conta os seguintes critérios: pronúncia, morfologia, sintaxe, vocabulário, fluência e impressão geral. Na grelha de avaliação fornecida aos avaliadores, cada critério era acompanhado de uma linha contínua de $9 \mathrm{~cm}$, com a designação "não nativo" na ponta esquerda e "nativo" na ponta direita, devendo o avaliador assinalar com uma cruz o grau de proximidade do excerto em apreciação ao nível nativo. A fim de assegurarmos que a ponta nativa da escala era interpretada tendo como ponto de referência 
verdadeiros falantes nativos de inglês, foram misturados, de modo aleatório, excertos de entrevistas com falantes nativos de origem australiana, norte-americana, inglesa e escocesa com os excertos das entrevistas dos falantes não nativos. Após a conclusão de todas as avaliações, os registos dos avaliadores foram transformados em valores discretos, através da sobreposição de um acetato com uma linha de $9 \mathrm{~cm}$ dividida numa escala de 18 pontos (1 ponto por $0.5 \mathrm{~cm}$ ). Os falantes de inglês L2 a quem todos os avaliadores atribuíram entre 16 e 18 pontos nos critérios sintaxe e morfologia e 15 ou mais pontos nos restantes critérios ${ }^{9}$, com o máximo de uma exceção ${ }^{10}$, foram considerados quase nativos. Aqueles que receberam entre 14 e 16 pontos nos critérios sintaxe e morfologia e 12 ou mais pontos nos outros critérios, com o máximo de uma exceção, foram classificados como avançados.

\subsection{Desenho experimental}

Todos os participantes foram sujeitos a uma bateria de tarefas experimentais que testavam, por um lado, o tipo de verbos intransitivos que admitem inversão locativa em inglês - inacusativo de existência e aparecimento vs. inacusativo de mudança de estado vs. inergativo redundante $v s$. inergativo não redundante ${ }^{11}-\mathrm{e}$, por outro, o tipo de contexto discursivo em que esta inversão é permitida - locativo tópico + sujeito foco estreito $v s$. locativo tópico + sujeito parte de foco largo vs. locativo foco + sujeito tópico vs. locativo foco + sujeito foco. Todas as tarefas incluíam 6 itens por condição e tantos distratores quanto itens experimentais. Nestes itens, foram usados PP locativos definidos com 3 palavras, verbos no passado simples e sujeitos indefinidos com 3 palavras (exceto na tarefa de priming sintático, em que tinha 2). Nas tarefas que testavam a variável "tipo de verbo", foram fornecidos contextos, com 20 a 24 palavras, que forçavam o sujeito e o verbo a serem interpretados como foco e o PP como tópico, uma vez que este é o contexto discursivo em que a inversão locativa é mais amplamente aceite. Por seu lado,

\footnotetext{
${ }^{9}$ Esta pontuação é semelhante à atribuída aos falantes nativos, que, ocasionalmente, receberam avaliações de 15 em critérios como fluência e pronúncia.

${ }^{10}$ As exceções são tipicamente no critério pronúncia.

${ }^{11}$ Os verbos usados foram os seguintes: (i) inacusativos de existência e aparecimento - come ('vir'), arrive ('chegar'), enter ('entrar'), appear ('aparecer'), emerge ('surgir, emergir'), live ('viver'); (ii) inacusativos de mudança de estado- break ('partir-se'), melt ('derreter'), smash ('esmagar-se'), defrost ('descongelar'), explode ('explodir'), burn ('queimar'); (iii) inergativos redundantes - swim ('nadar'), fly ('voar'), flutter ('esvoaçar'), glitter ('brilhar'), wave ('abanar'), tick ('fazer tique-taque'); (iv) inergativos não redundantes - meet ('conhecer'), shop ('fazer compras'), laugh ('rir'), cough ('tossir'), sneeze ('espirrar'), vomit ('vomitar').
} 
nas tarefas sobre a variável "contexto discursivo", foram usados inacusativos de existência e aparecimento em todos os itens experimentais ${ }^{12}$. A tabela 3 apresenta exemplos de itens para cada uma das condições testadas.

\begin{tabular}{|c|c|}
\hline Tipo de verbo intransitivo & Tipo de contexto discursivo \\
\hline $\begin{array}{l}\text { Inacusativo de existencia e aparecimento: As the music } \\
\text { started, our attention was attracted towards the wooden } \\
\text { stage of the theatre. Precisely at } 8 \text { o'clock, the curtain rose } \\
\text { and... on the stage appeared two gospel singers. }\end{array}$ & $\begin{array}{l}\text { Locativo tópico + sujeito parte de foco largo: testado } \\
\text { através dos itens usados para testar inacusativos de } \\
\text { existência e aparecimento nas tarefas sobre tipo de verbo, } \\
\text { uma vez que aí o sujeito e o verbo são foco e o PP tópico. }\end{array}$ \\
\hline $\begin{array}{l}\text { Inacusativo de mudança de estado: The first snow storm of } \\
\text { the season reached the streets of Chicago on Monday. } \\
\text { Yesterday the weather conditions significantly improved in } \\
\text { the city and } . . . \text { on the streets melted a lot of snow. }\end{array}$ & $\begin{array}{l}\text { Locativo tópico + sujeito foco estreito: A: Who lived in this } \\
\text { house? B: In this house lived two old ladies. }\end{array}$ \\
\hline $\begin{array}{l}\text { Inergativo redundante: To the right I could see the top of } \\
\text { one of Portland's many bridges, one I may have crossed } \\
\text { once but I can't recall. Above the bridge flew flocks of } \\
\text { seagulls. }\end{array}$ & $\begin{array}{l}\text { Locativo foco + sujeito tópico: A: Why is everybody talking } \\
\text { about our } 7 \text { th grade students? What happened? B: On BBC } \\
\text { news appeared some of them. }\end{array}$ \\
\hline $\begin{array}{l}\text { Inergativo não redundante: I have happy memories of my } \\
\text { childhood in Gary. Our home was located between the } \\
\text { pharmacy and Mr Smith's store. At this store shopped many } \\
\text { old ladies. }\end{array}$ & $\begin{array}{l}\text { Locativo foco + sujeito foco: A: Why was John's } \\
\text { bodyguard worried? What happened? B: In the mailbox } \\
\text { arrived a death threat. }\end{array}$ \\
\hline
\end{tabular}

Tabela 3: Exemplos de itens por condição

Foi aplicado neste estudo um total de cinco tarefas experimentais: uma tarefa drag \& drop, uma tarefa de priming sintático e uma tarefa de juízos de aceitabilidade rápidos sobre a variável "tipo de verbo" e uma tarefa drag \& drop e outra de juízos de aceitabilidade rápidos sobre a variável "tipo de contexto discursivo". Todas foram administradas presencialmente em dois computadores portáteis. Na tarefa drag \& drop, era apresentado aos participantes um contexto linguístico e pedido que usassem os blocos de palavras disponibilizados no ecrã, a fim de criarem um mínimo de 1 e o máximo de 4 continuações para o contexto fornecido.

\footnotetext{
12 Os verbos inacusativos de existência e aparecimento usados foram os mesmos listados na nota de rodapé anterior.
} 


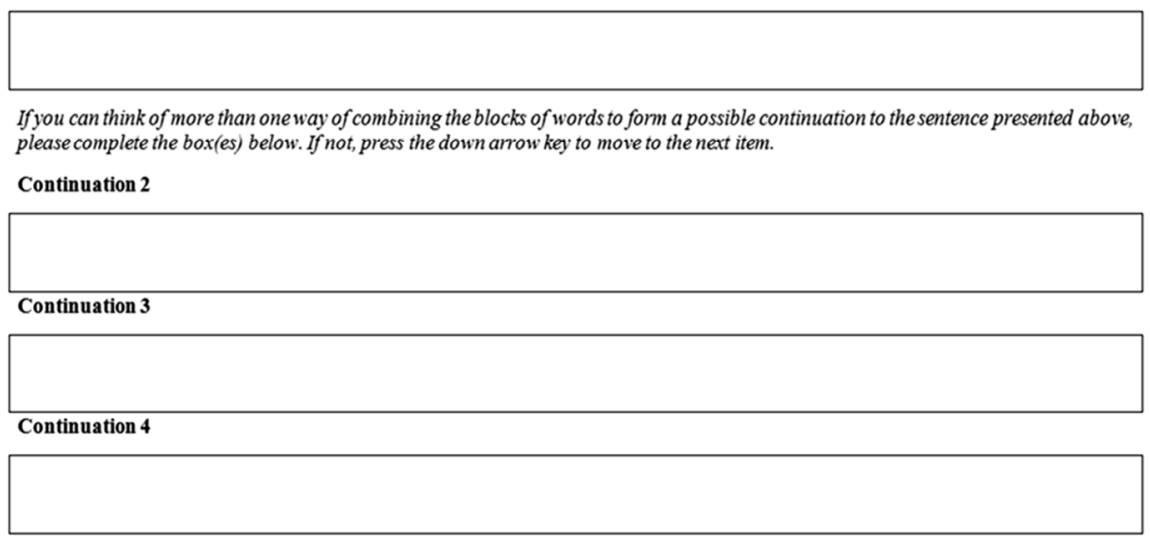

Figura 1: Item de uma tarefa drag \& drop

Na tarefa de priming sintático, ${ }^{13}$ que tem por base o modelo das tarefas de Schütter (2013), primeiro, os participantes tinham de ler em voz alta uma frase que aparecia no ecrã do computador durante 4 segundos - a frase prime. Em seguida, surgia uma imagem e era pedido aos participantes que indicassem, em 4 segundos, se esta correspondia ou não à frase lida em voz alta. Por último, aparecia uma outra imagem no ecrã, a qual tinha de ser descrita em 5 segundos, com recurso a uma única frase. Tendo em conta os resultados da investigação sobre priming sintático (cf. Branigan, 2007; Pickering \& Ferreira, 2008; Schütter, 2013), assumimos que, se a estrutura usada na frase prime fosse possível na gramática mental do falante, este tenderia a usá-la para descrever a imagem final de cada item.

\footnotetext{
${ }^{13}$ Priming sintático refere-se à tendência que os falantes têm de repetir o tipo de construção frásica usada numa frase imediatamente anterior.
} 

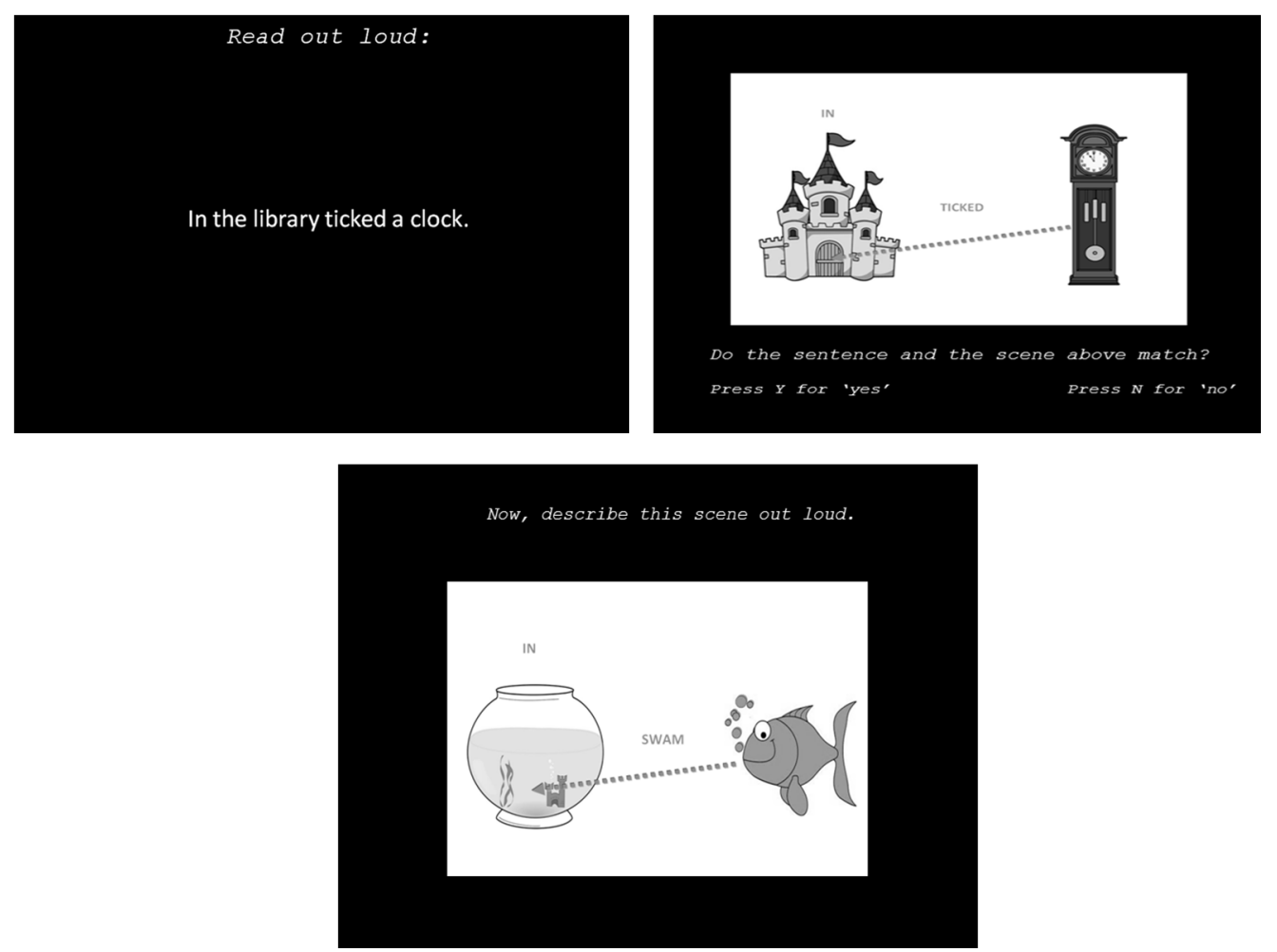

Figura 2: Item de exemplo da tarefa de priming sintático

Por fim, na tarefa de juízos de aceitabilidade rápidos, os participantes tinham de avaliar o mais depressa possível a aceitabilidade de uma frase que era apresentada palavra a palavra no centro do ecrã a um ritmo de 400 ms por palavra ${ }^{14}$. A avaliação era feita numa escala de 1 a 5 , em que 1 correspondia a "totalmente inaceitável" e 5 a "totalmente aceitável". Antes de aparecer a frase a ser avaliada, era pedido aos participantes que lessem silenciosamente o contexto que a antecedia, o qual era apresentado como um único bloco de palavras sem qualquer limite de tempo.

Dadas estas características, as tarefas que usámos não eram igualmente exigentes em termos de processamento linguístico. Enquanto, nas tarefas drag \& drop, os participantes tinham tempo suficiente para reanalisar as frases, acederem ao seu conhecimento linguístico e monitorizarem as suas repostas, nas restantes tarefas experimentais, a apresentação rápida dos

\footnotetext{
${ }^{14}$ Este é o ritmo tipicamente usado neste tipo de tarefas, uma vez que se assume que $400 \mathrm{~ms}$ é uma janela de tempo suficiente para os falantes completarem todos os processos de compreensão normais, como acesso lexical, integração sintática e interpretação semântica (cf. Bader \& Häussler, 2010; Hopp, 2007).
} 
estímulos e a rapidez exigida na resposta colocavam algum peso sobre os recursos de processamento do participante e não permitiam reanálise (cf. Bader \& Haussler, 2010; Hopp, 2007; Schütter, 2013). Por isso, estas poderão captar o tipo de opcionalidade predito pela HI, que pode não ser detetável em tarefas offline sem pressão de tempo, como a tarefa drag \& drop. O recurso a diferentes tipos de tarefas é, assim, fundamental para obtermos um retrato mais completo do que se passa na interface sintaxe-discurso em L2.

\subsection{Análise dos dados}

A análise estatística dos dados recolhidos através das tarefas experimentais acima apresentadas foi realizada com modelos de efeitos mistos, em que foram computados como efeitos fixos as variáveis grupo, tipo de verbo e tipo de contexto discursivo e como efeitos aleatórios as variáveis participantes e itens. Foram realizados dois tipos de análises com estes modelos: within-group e between-groups (i.e., entre um grupo experimental X e o grupo de controlo). Os efeitos fixos foram codificados com os seguintes códigos contrastivos (para mais detalhes sobre codificação em modelos de efeitos mistos, ver, por exemplo, Cunnings, 2012): 0.5 vs. -0.5 para contrastar dois níveis do mesmo efeito fixo (e.g., grupo de controlo $=0.5 v s$. grupo avançado de falantes de inglês L2 - PE L1 $=-0.5$; verbos inacusativos de mudança de estado $=0.5 v s$. verbos inacusativos de existência e aparecimento $=-0.5)$ e $0.75 v s$. -0.25 para contrastar um nível com três níveis do mesmo efeito fixo (e.g., verbos inergativos não redundantes $=0.75 \mathrm{vs}$. verbos inergativos redundantes $=-0.25+$ verbos inacusativos de mudança de estado $=-0.25+$ verbos inacusativos de existência e aparecimento $=-0.25$ ). Seguindo Cunnings (2012) e Linck e Cunnings (2015), as análises incluíram interceções aleatórias para participantes e itens, declives aleatórios por participante para as variáveis withinsubject, i.e., tipo de verbo e tipo de contexto, e declives aleatórios por item para a variável grupo (mas apenas nas análises between-groups). A análise estatística foi conduzida em R, usando o pacote $l m e 4$. Mais especificamente, foi usada a função lmer (modelo misto linear) para a análise dos resultados das tarefas de juízos de aceitabilidade rápidos e a função glmer (modelo misto linear generalizado), com a especificação "family=binomial", para a análise dos dados das restantes tarefas, uma vez que estas produzem resultados binários - presença / ausência de inversão locativa (codificados como PPVS = 1 e ausência de PPVS =0). Dado que a função glmer gera output com valores de $p$ e a função lmer apenas gera valores de $t$, usámos como 
medidas de significância os valores de $p$ e $t$. Como é habitual na literatura (cf. Linck \& Cunnings, 2015), um efeito fixo foi considerado estatisticamente significativo sempre que $p$ é inferior ou igual a 0.05 e $t$ é superior ou igual a $2.00^{15}$.

\section{Resultados}

\subsection{Estudo 1: Tipo de verbos intransitivos admitidos em inversão locativa}

No estudo sobre a distribuição dos verbos intransitivos em inversão locativa, o grupo de falantes monolingues de inglês distingue, em todas as tarefas, os verbos que admitem este tipo de inversão daqueles que não a permitem ( $p<0.001$ na tarefa drag \& drop; $p=0.00246$ na tarefa de priming, $t=-8.88$ na tarefa de juízos de aceitabilidade). A mesma consistência não é, contudo, encontrada nos resultados dos falantes de inglês L2. Como será descrito na presente subsecção, estes falantes comportam-se de modo diferente consoante as exigências impostas pela tarefa experimental.

Consideremos, em primeiro lugar, os resultados da tarefa drag \& drop apresentados na figura $3^{16}$. Nesta tarefa, todos os grupos de falantes de inglês L2 produzem inversão locativa significativamente mais com verbos inergativos redundantes e inacusativos de existência e de aparecimento do que com os restantes verbos testados (grupo de franceses com nível avançado - AV L1 FR: $p<0.001$; grupo de franceses com nível quase nativo - QN L1 FR: $p<0.001$; grupo de portugueses com nível avançado - AV L1 PE: $p<0.001$; grupo de portugueses com nível quase nativo - QN L1 PE: $p<0.001$ ), o que está em linha com o padrão de comportamento do grupo de falantes monolingues de inglês. Existe apenas um ponto em que os resultados dos falantes monolingues e os dos falantes de L2 não convergem: a produção de inversão locativa com verbos inergativos redundantes e inacusativos de existência e aparecimento. Nas condições que testam estes verbos, os falantes de inglês L2 produzem menos estruturas de inversão do que o grupo de monolingues (AV L1 FR: $p<0.001$; QN L1 FR: $p=0.00857$; AV L1 PE: $p=0.0020$;

\footnotetext{
${ }^{15}$ Note-se que, neste caso, um efeito fixo é significativo independentemente de o valor igual ou superior a 2.00 ser positivo ou negativo.

${ }^{16}$ Por razões de espaço, apenas apresentamos aqui os resultados relativos à ordem PPVS. No entanto, na tarefa drag \& drop, os grupos testados também produziram ordens SVPP e/ou PPSV em 100\% dos itens experimentais. O grupo de falantes avançados de inglês L2-PE L1 produziu ainda frases com as ordens VSPP e VPPS. Crucialmente, a análise dos resultados revelou que a diferença entre este grupo e o grupo de controlo relativamente à ordem $\mathrm{V}(\mathrm{PP}) \mathrm{S}(\mathrm{PP})$ não é estatisticamente relevante $(p=0.781)$.
} 
QN L1 PE: $\left.p=0.05743^{17}\right)^{18}$. Apesar desta divergência, e tendo em conta que os falantes de inglês L2 diferenciam claramente os verbos com os quais a inversão locativa é (im)possível, o seu comportamento na tarefa $d r a g \&$ drop pode ser caracterizado como quase nativo.

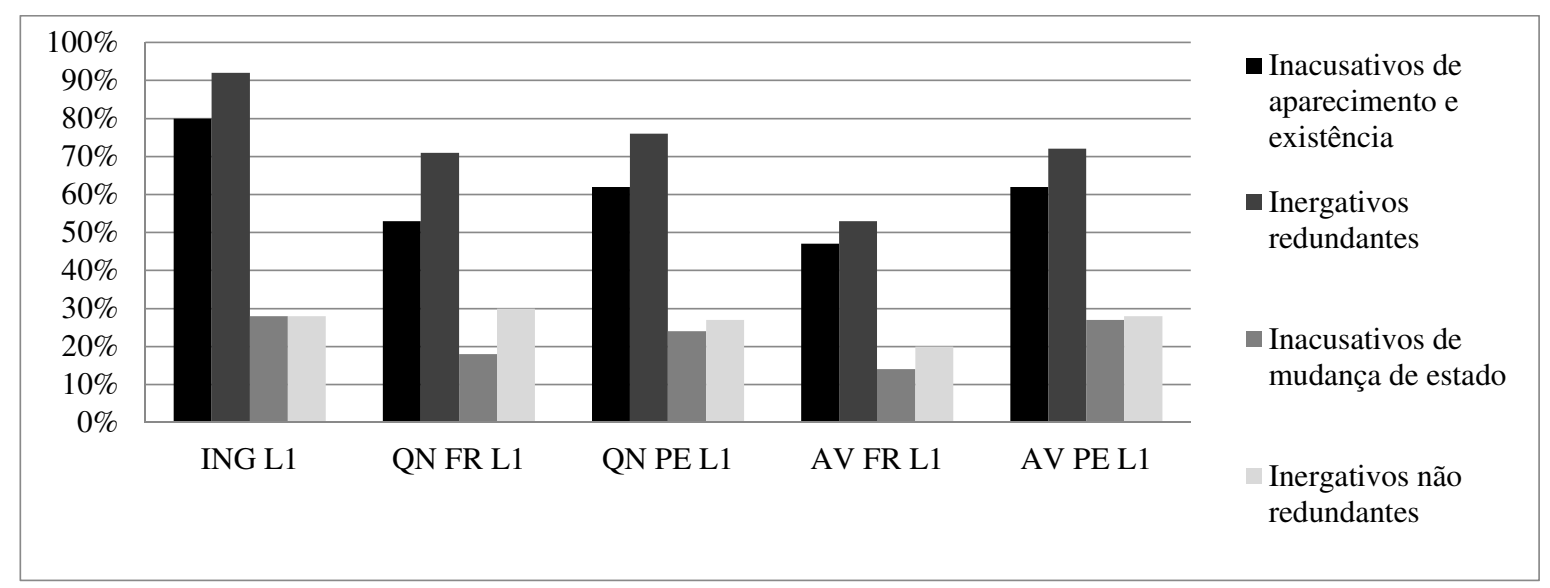

Figura 3: \% de estruturas de inversão locativa produzidas na tarefa drag \& drop por tipo de verbo e grupo

Na tarefa de priming sintático, de um modo geral, as taxas de produção de inversão locativa são inferiores às observadas na tarefa drag \& drop, mesmo no grupo de controlo (ver figura 4$)^{19}$. Possivelmente, isto acontece porque a tarefa de priming sintático que aplicámos envolve produção oral de frases descontextualizadas e, em inglês, a inversão locativa é tipicamente usada na escrita, particularmente em contextos em que o locativo é tópico e o sujeito foco (ver secção 3). A produção de inversão locativa nesta tarefa pode, por isso, ter sido percecionada pelos participantes como pouco natural, levando a que o efeito de priming sintático que pretendíamos criar tenha sido bloqueado em parte dos itens experimentais. Crucialmente, apesar das baixas taxas de produção de inversão locativa, nesta tarefa, o grupo de controlo faz uma distinção clara entre os verbos inergativos redundantes e inacusativos de aparecimento, por um lado, e os restantes verbos, por outro, produzindo mais inversão com os

\footnotetext{
${ }^{17}$ A diferença de resultados entre o grupo de falantes quase nativos inglês L2- PE L1 e o grupo de controlo a este respeito aproxima-se do limiar de significância estatística.

${ }^{18}$ Nas condições em que a inversão tende a ser rejeitada pelos falantes monolingues, não existem quaisquer diferenças estatisticamente relevantes entre os grupos experimentais e o grupo de controlo.

${ }^{19}$ Quando não produziam inversão locativa, os participantes produziam frases ou com a ordem SVPP ou a com a ordem PPSV. Nenhuma outra ordem de palavras foi produzida nesta tarefa.
} 
primeiros do que com os últimos ( $p=0.00246$ ). Os seus resultados estão, assim, em linha com os obtidos na tarefa drag \& drop. O mesmo não acontece com os resultados dos grupos de falantes de inglês L2. Enquanto que, na tarefa drag \& drop, todos estes grupos conseguem distinguir os verbos que permitem inversão locativa daqueles que não a admitem, na tarefa de priming sintático, só um o consegue: o grupo de falantes quase nativos de inglês L2 - francês L1 ( $p=0.0065)$. Ainda assim o desempenho destes falantes não é totalmente alvo, visto que produzem ligeiramente mais estruturas de inversão locativa com inacusativos de mudança de estado e inergativos não redundantes do que o grupo de controlo ( $p=0.096504$ - este valor aproxima-se de significância estatística).

Os restantes grupos de falantes de L2 testados exibem indeterminação quanto ao tipo de verbos compatíveis com inversão locativa. Os falantes avançados de inglês L2 - francês L1 produzem percentagens idênticas, mas baixas (entre $21 \%$ e $28 \%$ ), de inversão com verbos inacusativos de mudança de estado, inacusativos de existência/aparecimento e inergativos redundantes (inac. de aparecimento $v s$. de mudança de estado: $p=0.24031$; inerg. redundantes vs. inac. de mudança de estado: $p=0.19846$ ), revelando, deste modo, incapacidade de distinguir entre os três tipos de verbos, quando colocados sob pressão de tempo. Estes falantes apenas têm um comportamento diferente com os verbos inergativos não redundantes (inerg. não redundantes $v s$. restantes verbos $p=0.022$ ), que rejeitam categoricamente em inversão locativa (só 7\% das frases com estes verbos têm a ordem PPVS). À semelhança dos falantes de francês com nível avançado em inglês, os falantes de inglês L2 - PE L1 tratam de modo igual três classes de verbos: inacusativos de mudança de estado, inergativos redundantes e inergativos não redundantes (inerg. redundantes vs. não redundantes: AV PE L1 $p=0.3267$, QN PE L1 p= 0.458 ; inac. de mudança de estado vs. inerg. redundantes: AV PE L1 $p=0.77025, \mathrm{QN}$ PE L1 p= 0.197). Os verbos inacusativos de existência e aparecimento são os únicos que recebem um tratamento diferente por parte dos falantes portugueses, que produzem significativamente mais estruturas de inversão em inglês com estes verbos do que com os restantes (AV PE L1 $p=$ 0.0179, QN PE L1 $p=0.0212$ ). Dado que quer o grupo de falantes de PE, quer o grupo de falantes avançados de inglês L2 - francês L1 exibem baixas taxas de produção de inversão locativa em todas as condições, incluindo naquelas em que os monolingues permitem esta ordem de palavras, e não diferenciam, de forma consistente, as condições que são compatíveis com este 
tipo de inversão das que não o são, pode concluir-se que, nesta tarefa, o seu comportamento em relação à construção de inversão locativa é indeterminado ${ }^{20}$.

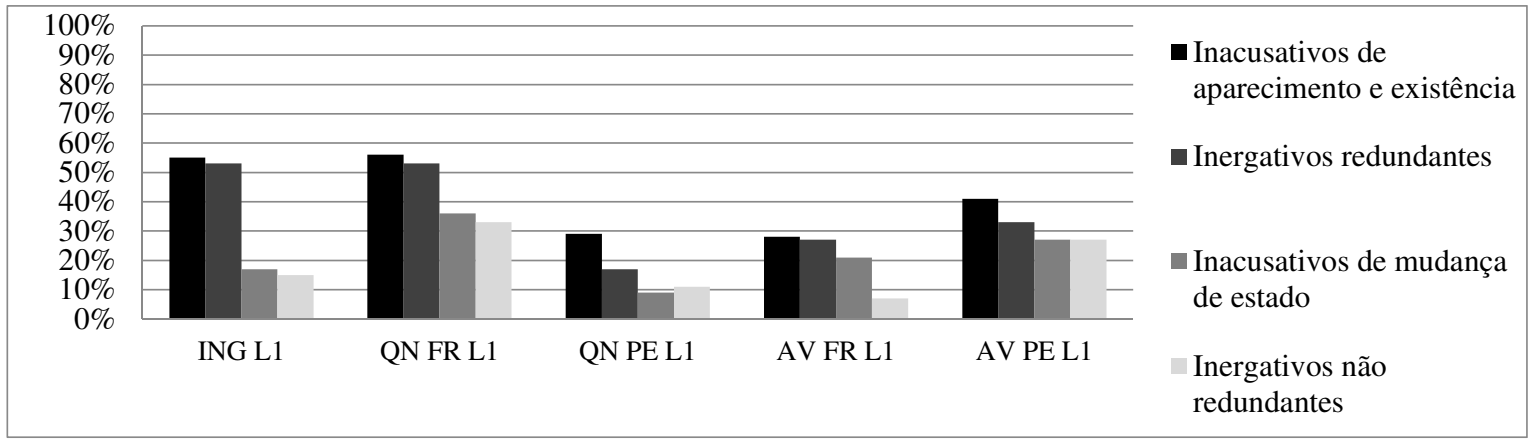

Figura 4: \% de estruturas de inversão locativa produzidas na tarefa priming sintático por tipo de verbo e grupo

Olhemos, por fim, para os resultados da tarefa de juízos de aceitabilidade rápidos apresentados na figura 5 e na tabela 3. Nesta tarefa, os falantes de inglês L2, tal como o grupo de controlo, atribuem pontuações superiores a estruturas de inversão locativa quando o verbo é um inergativo redundante ou um inacusativo de existência e aparecimento do que quando este pertence às outras subclasses verbais testadas (QN FR L1: $t=-4.843$; AV FR L1: $t=-3.536$; AV PE L1: $t=-4.224$; QN PE L1: $t=-3.836$ ). Apesar deste facto, as análises between-groups e a análise de resultados individuais revelam que os falantes de inglês L2 não têm um comportamento alvo na tarefa de juízos de aceitabilidade. As análises between-groups mostram que os grupos de falantes de inglês L2 - PE L1 aceitam inversão com inacusativos de mudança de estado e inergativos não redundantes significativamente mais do que os falantes monolingues (AV PE L1: $t=2.060$; QN PE L1 $t=1.672$ ), pelo que não é surpreendente que a tabela 4, que apresenta os resultados em medianas - medida de tendência central que indica a resposta média dos participantes -, mostre que os falantes de PE tendem a permitir inversão

\footnotetext{
${ }^{20}$ Note-se que, embora semelhantes, indeterminação e opcionalidade são dois fenómenos relativamente distintos. O comportamento de um grupo de falantes de L2 é indeterminado quando (i) os falantes exibem um nível baixo de aceitação /produção de uma estrutura $\mathrm{E}$ em todas as condições experimentais, incluindo naquelas em que o grupo de controlo a permite, e (ii) não distinguem entre as condições que são compatíveis com $E$ daquelas que não o são. Por seu lado, o comportamento de um grupo de L2 revela opcionalidade quando (i) não distingue entre as condições que são compatíveis com uma estrutura $E$ daquelas que não o são e (ii) tem um nível de aceitação/produção de E superior ao do grupo de controlo nas condições em que esta estrutura não é adequada (para mais detalhes, cf. Lozano, 2008).
} 
tanto com inergativos redundantes e inacusativos de existência e aparecimento (avaliação de aceitabilidade mediana $=5$ ), como com inergativos não redundantes e inacusativos de mudança de estado (avaliação de aceitabilidade mediana=4). Complementando as análises within e between groups dos resultados globais, a análise de resultados individuais revela que, ao contrário do que pode parecer à primeira vista, não são só os falantes de PE que exibem opcionalidade quanto aos tipos de verbo compatíveis com inversão locativa em inglês. Este fenómeno também ocorre, embora de forma mais residual, nos grupos de falantes de francês. De facto, $45 \%$ dos falantes quase nativos e $47 \%$ dos falantes avançados de inglês L2 - francês L1 têm medianas superiores a 3 em todas as condições experimentais, o que significa que aceitam inversão locativa com todos os tipos de verbo testados. No caso do grupo de inglês L2 - PE L1, as percentagens de falantes com medianas acima de 3 em todas as condições são ainda superiores: $47 \%$ de falantes avançados e $64 \%$ de falantes quase nativos. Crucialmente, esta opcionalidade não é encontrada no grupo de falantes monolingues de inglês. Apenas $8 \%$ destes falantes tem medianas superiores a 3 em todas as condições experimentais. A fim de determinar se estas diferenças entre falantes monolingues e falantes de L2 são significativas, conduzimos uma análise estatística dos dados individuais, codificados como $1=$ tem mediana superior a 3 em todas as condições e $0=$ não tem, com o teste não paramétrico Wilcoxon rank sum ${ }^{21}$. Este confirmou que as diferenças entre o grupo de monolingues e cada um dos grupos de falantes de L2 são estatisticamente relevantes (ING L1 vs. AV FR L1: $p=0.004378$; ING L1 vs. QN FR L1: $p=0.008802$; ING L1 vs. AV PE L1: $p=0.003329$; ING L1 vs. QN PE L1: $p<0.001)$. Assim, pode concluir-se que todos os grupos de falantes de L2 testados exibem algum nível de opcionalidade quanto aos tipos de verbo compatíveis com inversão locativa quando são colocados sob pressão de tempo.

\footnotetext{
${ }^{21}$ Não usámos aqui modelos de efeitos mistos, uma vez que estes não convergiram quando tentámos testar os contrastes entre o grupo de controlo e alguns grupos experimentais. Optámos por recorrer ao teste Wilcoxon rank sum, porque este é o mais apropriado para ser usado em casos como este, em que se pretende comparar dois grupos independentes que não têm uma distribuição normal (cf. Loewen \& Plonsky, 2016).
} 


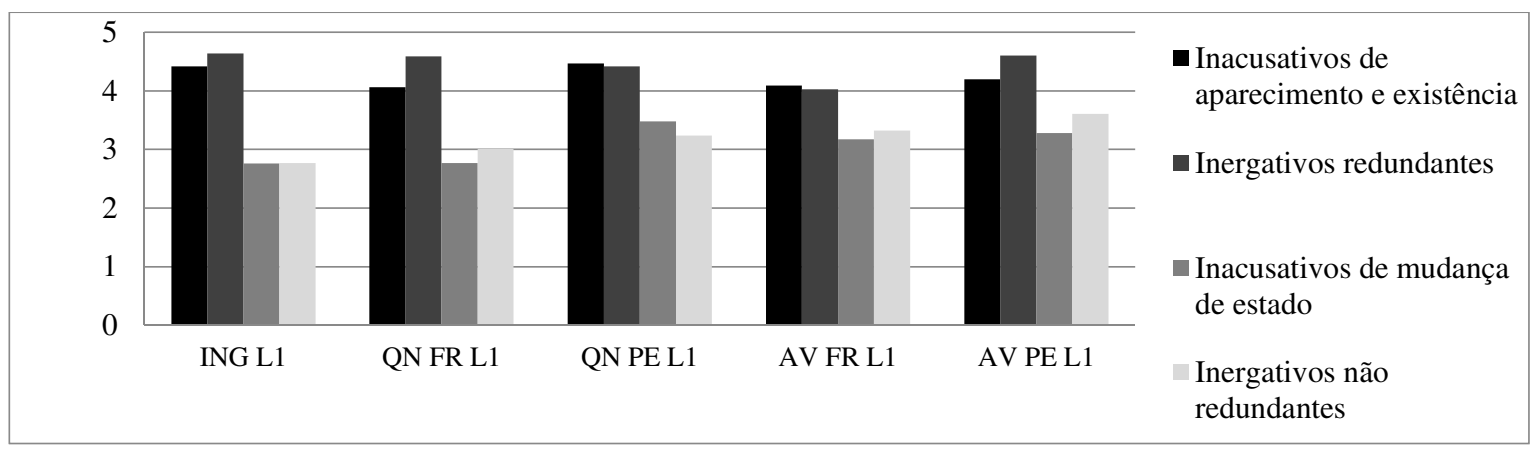

Figura 5: Média de aceitação de inversão locativa na tarefa de juízos de aceitabilidade por tipo de verbo e grupo

\begin{tabular}{lcccccc}
\hline \multicolumn{1}{c}{ Verbos } & ING L1 & QN FR L1 & AV FR L1 & QN PE L1 & AV PE L1 \\
\hline Inacusativos de aparecimento e existência & 5 & 4 & 5 & 5 & 5 \\
Inacusativos de mudança de estado & 3 & 2 & 3 & 4 & 4 \\
Inergativos redundantes & 5 & 5 & 5 & 5 & 5 \\
Inergativos não redundantes & 3 & 3 & 4 & 4 & 4 \\
\hline
\end{tabular}

Tabela 4: Mediana de aceitação de inversão locativa na tarefa de juízos de aceitabilidade por tipo de verbo e grupo

\subsection{Estudo 2: Tipo de contextos discursivos que admitem inversão locativa}

À semelhança do que se observou no conjunto de tarefas experimentais apresentadas acima, no estudo que se debruça sobre o tipo de contextos discursivos compatíveis com inversão locativa, o grupo de falantes monolingues de inglês tem um padrão de comportamento semelhante em tarefas com diferentes graus de exigência do ponto de vista do processamento linguístico. Estes permitem inversão locativa quer nos contextos em que o locativo é tópico e o sujeito é parte de foco largo, quer naqueles em que o sujeito recebe foco estreito, embora exibam uma preferência mais forte pelos primeiros ${ }^{22}(p=0.00245$ na tarefa drag \& drop; $t=-1.924$ na tarefa de juízos de aceitabilidade). Nos restantes contextos testados, i.e., locativo tópico + sujeito foco e locativo foco + sujeito foco, os falantes monolingues não aceitam inversão. Enquanto este grupo faz consistentemente uma distinção entre os contextos em que o locativo

\footnotetext{
${ }^{22}$ É possível que esta diferença entre o contexto em que o sujeito é parte de foco largo e aquele em que é foco estreito se deva ao facto de os itens que testam o primeiro incluírem contextos prévios mais característicos de um registo escrito relativamente formal, enquanto os que testam o último são antecedidos por interrogativas parciais, que são mais usadas na oralidade (ver secção 4.3).
} 
é tópico e o sujeito foco (estreito ou largo) e os restantes contextos discursivos $(p<0.001$ na tarefa drag \& drop; $t=-8.198$ na tarefa de juízos de aceitabilidade), os grupos de falantes de inglês L2 nem sempre fazem esta distinção. Como será mostrado em seguida, o desempenho destes grupos, de um modo geral, varia de acordo com o peso que a tarefa coloca sobre os seus recursos de processamento.

Na tarefa $d r a g$ \& $d r o p^{23}$, o grupo de falantes quase nativos de inglês L2 - francês L1 e o de falantes avançados de inglês L2-PE L1 são os únicos que diferenciam cada um dos contextos em que a inversão locativa é aceitável daqueles em que é discursivamente desadequada (AV L1 PE: $p<0.001$; QN L1 FR: $p=0.00182$ ). Apesar de terem, tal como os falantes monolingues, uma preferência por produzir inversão no contexto em que o sujeito e o verbo são foco e o locativo tópico (AV L1 FR: $p=0.091485^{24}$; QN L1 PE: $p=0.00103$ ) e de rejeitarem esta ordem de palavras quando o sujeito é tópico (AV L1 FR: $p=0.02491$; QN L1 PE: $p=0.00551$ ), os restantes grupos de falantes de inglês L2 testados tratam do mesmo modo dois contextos que não são considerados igualmente compatíveis com inversão locativa pelos falantes monolingues: o contexto em que o sujeito recebe foco estreito e o contexto em que toda a frase é foco (AV L1 FR: $p=0.23765$; QN L1 PE: $p=0.513$ ). O comportamento destes grupos é, assim, caracterizado por alguma opcionalidade. Por seu lado, o desempenho dos grupos de falantes quase nativos de inglês L2 - francês L1 e de falantes avançados de inglês L2- PE L1 pode ser caracterizado como quase nativo, uma vez que só divergem do grupo de monolingues relativamente a um aspeto: produzem menos inversão locativa do que os monolingues nas condições que testam os contextos locativo tópico + sujeito foco (estreito e largo) (AV L1 PE vs. L1 ING: $p=0.00897$; QN L1 FR $v s$. L1 ING: $p=0.0085$ ).

\footnotetext{
${ }^{23}$ Por razões de espaço, apenas apresentamos aqui os resultados relativos à ordem PPVS. No entanto, nesta tarefa drag \& drop, os grupos testados também produziram ordens SVPP e/ou PPSV em todos os itens experimentais. O grupo de falantes avançados de inglês L2-PE L1 produziu ainda frases com as ordens VSPP e VPPS. Crucialmente, a análise dos resultados revelou que a diferença entre este grupo e o grupo de controlo relativamente à ordem $\mathrm{V}(\mathrm{PP}) \mathrm{S}(\mathrm{PP})$ não é estatisticamente relevante $(p=0.891)$.

${ }^{24}$ Este valor de $p$ aproxima-se do limiar de significância estatística.
} 


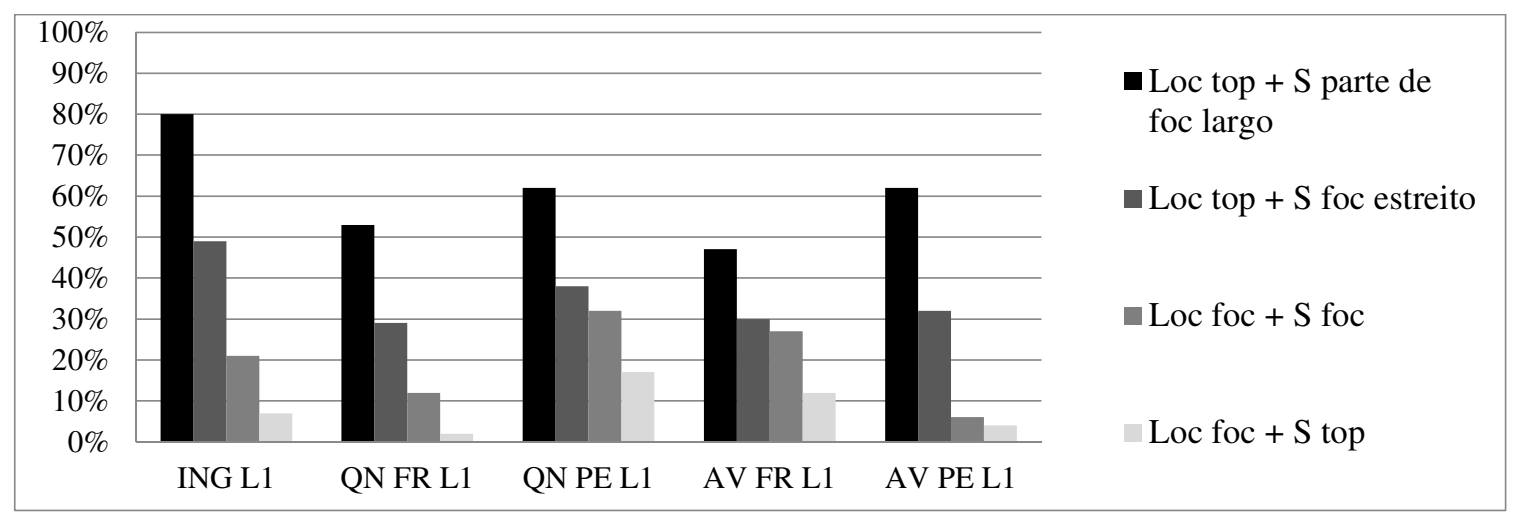

Figura 6: \% de estruturas de inversão locativa produzidas na tarefa drag \& drop por tipo de contexto discursivo e grupo

Os resultados obtidos na tarefa de juízos de aceitabilidade rápidos são significamente diferentes dos da tarefa drag \& drop. Ao contrário do que acontece nesta última, na tarefa de juízos de aceitabilidade, todos os grupos de falantes de inglês L2 exibem opcionalidade entre certos contextos que não são considerados igualmente compatíveis com inversão locativa pelos falantes monolingues, nomeadamente entre o contexto locativo tópico + sujeito em foco largo e o contexto locativo foco + sujeito foco, no caso do grupo de portugueses com nível avançado em inglês (AV PE L1 $t=1.69$; mas ING L1 $t=6.478$ ), e entre o contexto em que o sujeito recebe foco estreito e o contexto locativo foco + sujeito foco, no caso dos restantes grupos (QN FR L1 $t=-0.377$; AV FR L1 $t=0.707$; QN PE L1 $t=1.506$; mas ING L1 $t=4.66$ ). Apesar destas diferenças entre os grupos de falantes de inglês L2 e o de falantes monolingues de inglês, existem dois aspetos em que os resultados de todos estes grupos convergem: primeiro, todos rejeitam claramente inversão locativa no contexto em que o locativo é foco e o sujeito tópico (diferença entre os resultados neste contexto e nos restantes: QN FR L1 $t=5.319$; AV FR L1 $t=$ 3.492; QN PE L1 $t=3.573$; AV EP L1 $t=3.56$; L1 ING $t=4.851$ ); e, segundo, com a exceção do grupo de portugueses com nível avançado em inglês, todos os grupos revelam uma preferência por contextos em que o locativo é tópico e o verbo e o sujeito são foco (diferença entre os resultados neste contexto e nos restantes: QN FR L1 $t=-3.678$; AV FR L1 $t=-2.49$; QN PE L1 $t=-3.245$; AV EP L1 $t=-1.534$; L1 ING $t=-4.092$ ). 


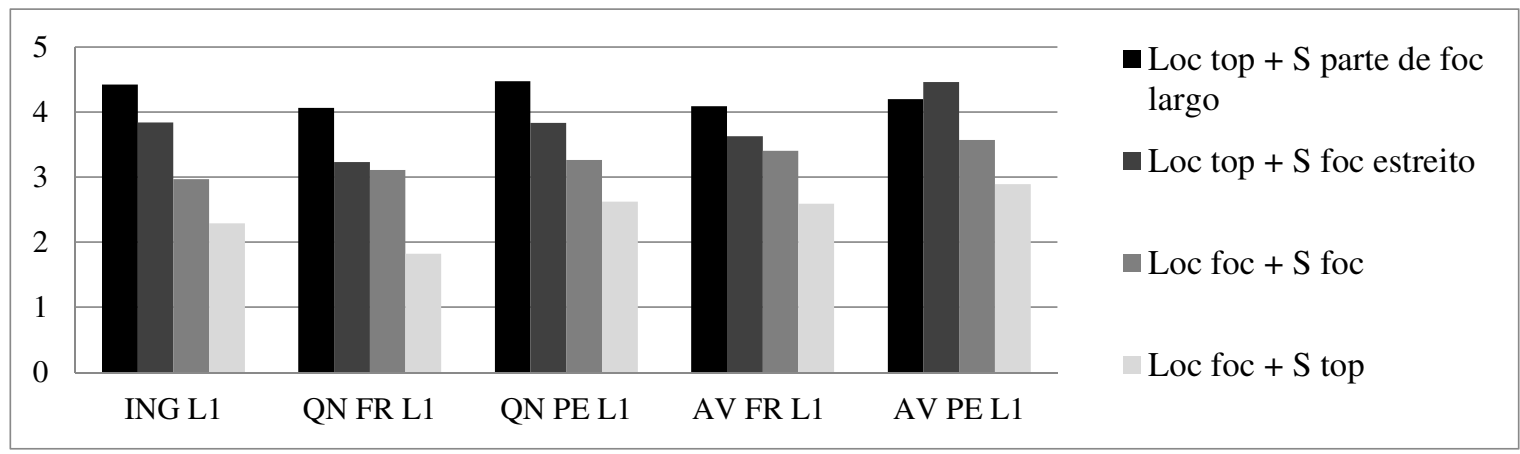

Figura 7: Média de aceitação de inversão locativa na tarefa de juízos de aceitabilidade por tipo de contexto discursivo e grupo

Confirmando o padrão de opcionalidade percetível nos resultados por grupo, a análise dos resultados individuais da tarefa de juízos de aceitabilidade rápidos mostra que, em cada grupo experimental, existe uma percentagem expressiva de falantes de inglês L2 que tem medianas superiores a 3 em todas as condições em que o sujeito é interpertado como (parte do) foco ( i.e., os contextos locativo tópico + sujeito em foco largo, locativo tópico + sujeito foco estreito e locativo foco + sujeito foco). Nos grupos de falantes franceses de inglês L2, este padrão de comportamento é exibido por $60 \%$ dos falantes avançados e $45 \%$ dos quase nativos. Já nos grupos de falantes portugueses de inglês L2, as percentagens de participantes com medianas superiores a $3 \mathrm{em}$ todas as condições em que o sujeito é (parte do) foco são ainda superiores: $71 \%$ no grupo de avançados e $64 \%$ no grupo de nível quase nativo. Em contraste, no grupo de falantes monolingues, só $16 \%$ dos participantes exibe este tipo de comportamento. De acordo com os resultados do teste estatístico não paramétrico Wilcoxon rank sum, a diferença entre os falantes monolingues e os falantes de L2 a este respeito é estatisticamente significativa em todos os casos, exceto num - no do grupo de falantes quase nativos de inglês L2 - francês L1 (ING L1 vs. AV FR L1: $p=0.004758$; ING L1 vs. AV PE L1: $p=0.005163$; ING L1 vs. QN PE L1: $p=0.0004353)$. Ainda assim, a diferença entre este grupo e o grupo de monolingues aproxima-se do limiar de significância estatística $(p=0.06712)$. Em conjunto, os resultados individuais e por grupo da tarefa de juízos de aceitabilidade indicam que, quando colocados sob pressão de tempo, todos os grupos de falantes de inglês L2 tendem a aceitar inversão locativa de acordo com o estatuto [+ foco] do sujeito e sem ter em conta o estatuto discursivo do locativo, que é um fator considerado pelos falantes monolingues de inglês. Por este motivo, todos os grupos de falantes de inglês L2 exibem, ainda que em graus diferentes, 
opcionalidade entre o contexto locativo foco + sujeito foco, que não é tipicamente aceite pelos monolingues, e outros contextos em que a inversão locativa é adequada.

Em síntese, tanto no estudo sobre a variável "tipo de verbo", como no estudo sobre a variável "tipo de contexto discursivo" os grupos de falantes de inglês L2 têm um desempenho diferente de acordo com o peso que a tarefa coloca sobre os seus recursos de processamento. Nas tarefas sem limite de tempo, os grupos de L2 tendem a ter um comportamento quase nativo. Em contraste, nas tarefas com pressão de tempo, todos exibem, ainda que em graus substancialmente diferentes, opcionalidade quanto aos tipos de verbos e de contextos discursivos compatíveis com a inversão locativa do inglês, como mostra a tabela 5. Dado que, ao contrário dos grupos de falantes de L2, os falantes monolingues de inglês distinguem em todas as tarefas os verbos e contextos discursivos compatíveis com este tipo de inversão daqueles que não o são, pode concluir-se que a variabilidade observada nos resultados dos grupos de falantes de inglês L2 não é uma consequência das opções metodológicas feitas neste trabalho, mas sim de reais diferenças linguísticas entre falantes de L1 monolingues e falantes de L2 na interface sintaxe-discurso.

Ainda que os falantes monolingues não manifestem opcionalidade nas tarefas com maior carga cognitiva, poderia questionar-se se, em tarefas do mesmo tipo sobre propriedades "puramente" sintáticas, os falantes de L2 não exibiriam também opcionalidade. Esta hipótese é, contudo, afastada pelos resultados obtidos num estudo sobre sujeitos nulos e inversão "livre" em inglês L2, em que testámos exatamente os mesmos indivíduos que participaram nas experiências reportadas no presente artigo usando tarefas drag \& drop e de juízos de aceitabilidade rápidos (Teixeira, 2016a). Este estudo revela que, quando colocados sob pressão de tempo, os falantes avançados de inglês L2 - PE L1 aceitam, em inglês, inversão livre, em particular no contexto de foco estreito, e sujeitos nulos inanimados e expletivos. Crucialmente, o grupo de falantes quase nativos de inglês L2-PE L1, os grupos de falantes avançados e quase nativos de inglês L2 - francês L1 e o grupo de falantes monolingues de inglês rejeitam claramente sujeitos nulos e inversão livre em todas as tarefas. Estes resultados permitem-nos, assim, concluir que as diferenças entre falantes monolingues e falantes quase nativos de L2 reportadas no presente artigo não são transversais a todos os domínios linguísticos. 


\begin{tabular}{|c|c|c|c|c|c|}
\hline \multirow{2}{*}{ Variável } & \multirow{2}{*}{ Tarefa } & \multicolumn{2}{|c|}{ Falantes quase nativos } & \multicolumn{2}{|c|}{ Falantes avançados } \\
\hline & & $\operatorname{Fr} L 1$ & PE L1 & $\operatorname{Fr} L 1$ & PE L1 \\
\hline \multirow{3}{*}{$\begin{array}{c}\text { Tipo de verbo } \\
\text { intransitivo }\end{array}$} & Drag \& drop 1 & Quase nativo & Quase nativo & Quase nativo & Quase nativo \\
\hline & Priming sintático & Quase nativo & Indeterminação & Indeterminação & Indeterminação \\
\hline & $\begin{array}{c}\text { Juízos de } \\
\text { aceitabilidade rápidos } \\
1\end{array}$ & Opcionalidade & Opcionalidade & Opcionalidade & Opcionalidade \\
\hline \multirow[b]{2}{*}{$\begin{array}{c}\text { Tipo de contexto } \\
\text { discursivo }\end{array}$} & Drag \& drop 2 & Quase nativo & Opcionalidade & Opcionalidade & Quase nativo \\
\hline & $\begin{array}{c}\text { Juízos de } \\
\text { aceitabilidade rápidos } \\
2\end{array}$ & Opcionalidade & Opcionalidade & Opcionalidade & Opcionalidade \\
\hline
\end{tabular}

Tabela 5: Resultados de todas as tarefas experimentais

\section{Discussão}

Em conjunto, os resultados do presente trabalho sobre inversão locativa em inglês L2 infirmam a HLI e apoiam (pelo menos, em parte) as predições da HI sobre o estádio final do processo de aquisição de L2 na interface sintaxe-discurso. Por um lado, o facto de todos os grupos de falantes de inglês L2 exibirem opcionalidade relativamente quer aos tipos de verbos que admitem inversão locativa - que são os mesmos em inglês e francês e diferentes em PE -, quer aos tipos de contextos discursivos compatíveis com esta estrutura - que são os mesmos nas três línguas -, indica que, tal como predito pela HI, a interface sintaxe-discurso é um locus de opcionalidade em aquisição de L2, mesmo quando L1 e L2 são semelhantes. Por outro lado, o facto de, no estudo sobre a variável "tipo de verbo", os falantes de inglês L2 só exibirem opcionalidade nas tarefas com pressão de tempo e o facto de, no estudo sobre a variável "contexto discursivo", haver mais grupos que manifestam este padrão de comportamento quando colocados sobre pressão de tempo do que quando não estão sujeitos a tal pressão sugerem que a opcionalidade exibida pelos falantes de L2 está relacionada com ineficiências de processamento, tal como predito pela HI.

Note-se que, como a inversão locativa, em geral, e as propriedades testadas neste trabalho, em particular, não são tipicamente ensinadas em cursos de inglês, é altamente improvável que os falantes de inglês L2 tenham conhecimento explícito sobre as mesmas. Consequentemente, é também improvável que o seu desempenho seja mais convergente com a língua alvo nas tarefas $d r a g \&$ drop por estas lhes darem mais tempo do que as restantes para acederem a conhecimento explícito sobre as propriedades testadas. Dado que, pelos motivos 
que acabámos de explicar, é pouco provável que as diferenças de resultados entre as tarefas usadas neste trabalho sejam fruto do facto de cada uma delas poder convocar tipos distintos de conhecimento linguístico sobre inversão locativa, propomos que a explicação mais plausível para estas diferenças é a de que se devem ao facto de os três tipos de tarefas usados colocarem diferentes cargas sobre os recursos de processamento dos falantes. Como a HI prediz e os resultados do presente trabalho confirmam, quanto mais exigente a tarefa é em termos de processamento, menos eficientes são os falantes de L2 a integrar informação sintática com informação contextual e, por conseguinte, mais opcionalidade tendem a manifestar.

Embora os resultados dos falantes de L2 estejam, de um modo geral, em linha com as predições da HI, há uma condição experimental em que o seu comportamento não é consistente com esta hipótese: a condição que testa verbos inergativos não redundantes. Como explicado na secção 3, a inaceitabilidade destes verbos na inversão locativa do inglês é determinada por um fator léxico-sintático: estes verbos selecionam argumentos externos e não internos. Por este motivo, a HI prediria que os falantes quase nativos de inglês tivessem um comportamento alvo em relação a estes verbos. Contudo, não é isto que acontece. Como descrito em 4.1., embora todos os grupos de L2 tenham um comportamento alvo relativamente aos verbos inergativos não redundantes na tarefa $d r a g$ \& drop, na tarefa de juízos de aceitabilidade rápidos, os falantes quase nativos de inglês L2 - PE L1atribuem, em mediana, uma avaliação de 4 aos itens que testam a aceitabilidade de inversão locativa com estes verbos. Simultaneamente, nesta tarefa, há ainda uma percentagem significativa (45\%) de falantes quase nativos de inglês L2 - francês L1 que tem uma mediana superior a 3 nos itens com verbos inergativos não redundantes. Em conjunto, estes resultados sugerem que, ao contrário do que a HI propõe, as ineficiências na integração de informação sintática com informação discursiva podem resultar em problemas não só no domínio discursivo, mas também sintático.

Para além de colocarem em causa a ideia de que os problemas na interface sintaxediscurso se manifestam necessariamente em domínios externos à sintaxe, os resultados obtidos neste trabalho mostram que o grau de eficiência dos falantes de L2 na integração de informação sintática com informação discursiva é influenciado por vários fatores que não têm sido explorados pela HI. Um desses fatores é a quantidade e/ou distância da informação discursiva a ser processada pelo falante. $\mathrm{O}$ facto de, no presente trabalho, haver mais grupos de falantes de L2 que manifestam opcionalidade na tarefa drag \& drop sobre a variável "contexto 
discursivo" do que na tarefa do mesmo tipo sobre a variável "verbo", aliado ao facto de estes grupos tenderem a exibir ligeiramente mais opcionalidade na tarefa de juízos de aceitabilidade sobre a primeira variável do que sobre a última, indica que, quanto maior a quantidade e/ou mais distante ${ }^{25}$ estiver a informação contextual necessária para se escolher entre diferentes opções sintáticas, mais dificuldades tem o falante de L2 em integrar informação contextual e sintática eficientemente e, em consequência, maior é o grau de opcionalidade no seu desempenho linguístico. Note-se que, para decidir se um verbo é ou não discursivamente adequado, o falante tem apenas de ter em conta o significado do mesmo no contexto intrafrásico (e.g., swim 'nadar' é adequado com um sujeito que prototipicamente nada como a goldfish 'um peixinho-dourado', mas não com a student 'um estudante'), ao passo que, para decidir se um contexto discursivo é ou não compatível com inversão locativa, necessita de analisar o contexto interfrásico e determinar se o locativo é pressuposto e o sujeito foco nesse contexto particular. Presumivelmente, esta última tarefa exige a mobilização de mais recursos cognitivos do que a primeira, o que pode levar a que, neste caso, a carga associada à integração de informação sintática com informação contextual exceda mais frequentemente os recursos cognitivos disponíveis, originando ineficiências de processamento e, por conseguinte, opcionalidade ${ }^{26}$.

Outro dos fatores que influencia o desempenho dos falantes de L2 na interface sintaxediscurso é a L1. Por revelar que os grupos de falantes de inglês L2 - PE L1 exibem mais opcionalidade do que os grupos de falantes de inglês L2 - francês L1, os resultados do presente trabalho sugerem que o grau de eficiência na integração de informação sintática com informação discursiva é menor quando a L1 e a L2 são diferentes nas propriedades relevantes do que quando são semelhantes. Assumindo com Sorace $(2011,2016)$ que a integração de

\footnotetext{
${ }^{25}$ Dado que o falante tem de processar mais informação contextual e informação que está mais distante para decidir se a inversão locativa é adequada num dado contexto discursivo do que para determinar se um dado verbo é aceitável neste tipo de estrutura, a diferença de resultados entre estas variáveis pode dever-se ou à distância da informação contextual ou à sua quantidade ou ainda a ambos os fatores.

${ }^{26} \mathrm{O}$ facto de os falantes de L2 rejeitarem claramente inversão locativa no contexto em que o locativo é foco e o sujeito tópico não contradiz esta proposta. Note-se que, como, nos itens experimentais que testam este contexto, $o$ sujeito incluia sempre um pronome pessoal (e.g., On BBC News appeared some of them 'Na BBC News apareceram alguns deles'), o participante podia inferir que o sujeito veiculava informação mais pressuposta do que o locativo, mesmo sem ter em conta o contexto prévio. No caso dos restantes contextos, pelo contrário, era necessário que considerasse o contexto interfrásico para poder determinar o estatuto discursivo do sujeito e do locativo e, subsequentemente, avaliar se a inversão locativa era ou não discursivamente adequada naquele contexto particular.
} 
informação sintática com informação pragmático-discursiva depende, pelo menos, em parte, do mesmo conjunto de recursos cognitivos usados pelos falantes para inibirem a sua L1 enquanto usam a L2, propomos, a título especulativo, que as diferenças entre L1 e L2 afetam negativamente a eficiência do falante na integração de informação sintática e discursiva, porque este poderá ter de mobilizar mais recursos cognitivos para inibir a sua L1 quando a estrutura ativada é diferente na $\mathrm{L} 2^{27}$, o que deixará menos recursos disponíveis para outras tarefas linguísticas. Logicamente, quanto menos forem os recursos cognitivos disponíveis, mais provável será que ocorram ineficiências na integração de informação sintática e discursiva. Note-se que, ao contrário da HLI, a hipótese aqui levantada não prediz que, quando a L1 e a L2 são semelhantes, os falantes avançados/quase nativos terão um desempenho alvo na interface sintaxe-discurso. Esta hipótese prediz antes que, nestas circunstâncias, os falantes terão menos dificuldades na integração de informação sintática e contextual, o que levará a que exibam menos opcionalidade. Como observado neste trabalho, tal opcionalidade poderá apenas surgir em tarefas que colocam algum peso extra sobre os recursos de processamento do falante e que, por isso, criam maior competição por recursos cognitivos.

Finalmente, há um outro fator relacionado com o perfil linguístico do falante que parece afetar o sucesso na interface sintaxe-discurso - o nível de proficiência na L2. O facto de, no presente estudo, os falantes de nível avançado tenderem a exibir opcionalidade em mais tarefas e em maior grau do que os falantes de nível quase nativo ${ }^{28}$ sugere que, quanto menor o nível de proficiência é, mais provável é que um falante de L2 não seja consistentemente eficiente a integrar informação sintática e discursiva. É possível que isto aconteça, porque, quanto menos avançado é o nível de proficiência do falante, mais dominante é a sua L1 em relação à L2 e, por conseguinte, mais recursos cognitivos tem de mobilizar para a inibir. Por este motivo, em níveis de proficiência menos avançados, presumivelmente, existirão menos recursos disponíveis para serem usados na integração de informação sintática e discursiva, o que, por sua vez, levará a que haja mais ineficiência neste processo e, portanto, mais opcionalidade.

\footnotetext{
${ }^{27}$ Tendo em conta os resultados de Slabakova (2015), é possível que não seja só a diferença entre L1 e L2 que seja relevante, mas também o grau de marcação da estrutura/regra na L1. Estruturas/regras menos marcadas poderão ser mais difíceis de inibir do que estruturas/regras marcadas.

${ }^{28} \mathrm{O}$ comportamento dos grupos de falantes avançados e quase nativos de inglês L2-PE L1 na tarefa drag \& drop 2 é uma exceção a esta regra, para a qual não temos uma boa explicação no momento.
} 


\section{Conclusão}

Em conclusão, os resultados deste trabalho sobre a aquisição de inversão locativa em inglês avançado e quase nativo mostram que a interface sintaxe-discurso é necessariamente um locus de opcionalidade em aquisição de L2, mesmo quando L1 e L2 são semelhantes, tal como predito pela HI e contra a HLI. Os resultados obtidos são ainda consistentes com a nova versão da HI, que tem vindo a ser desenvolvida por Sorace $(2011,2016)$ ao longo dos últimos anos, de acordo com a qual a opcionalidade na interface sintaxe-discurso/pragmática é fruto de ineficiências de processamento motivadas pelo bilinguismo. Há, contudo, um ponto em que os resultados do presente estudo não estão em linha com a HI: a localização dos problemas na interface sintaxediscurso. Contrariamente ao que esta hipótese prediz, os resultados obtidos nas tarefas sobre a variável "tipo de verbo" sugerem que as ineficiências na integração de informação sintática com informação discursiva podem causar problemas não só no domínio discursivo, mas também sintático. Além de colocar em causa a ideia de que os problemas na interface sintaxediscurso se manifestam exclusivamente em domínios externos à sintaxe, o presente trabalho mostra ainda que existem três fatores, em parte ignorados na literatura sobre a $\mathrm{HI}^{29}$, que influenciam o grau de eficiência dos falantes de L2 na integração de informação sintática e discursiva: (i) a distância entre L1 e L2 (L1 $\neq$ L2 $\rightarrow$ menos eficiência $\rightarrow$ mais opcionalidade), (ii) o nível de proficiência na L2 (nível baixo de proficiência $\rightarrow$ menos eficiência $\rightarrow$ mais opcionalidade), e (iii) a quantidade e/ou distância da informação contextual a ser processada (muita informação num contexto interfrásico $\rightarrow$ menos eficiência $\rightarrow$ mais opcionalidade). Dado que, dependendo da combinação destes fatores, os falantes de L2 podem exibir diferentes graus de opcionalidade na interface sintaxe-discurso, em certos casos, essa opcionalidade é detetável por tarefas offline sem restrições de tempo, ao passo que, noutros, só tarefas offline mais exigentes em termos de processamento poderão captar este fenómeno. Este facto poderá explicar por que razão têm surgido estudos com resultados tão contraditórios sobre a interface sintaxe-discurso em L2.

\footnotetext{
${ }^{29}$ Note-se que o nível de proficiência tem sido tido em conta em alguns trabalhos sobre a $\mathrm{HI}$ e na própria conceptualização desta hipótese (cf. Sorace, 2011).
} 


\section{Referências}

Bader, M., \& J. Häussler (2010) Toward a model of grammaticality judgments. Journal of Linguistics, 46(2), pp. 273-330.

Belletti, A., E. Bennati \& A. Sorace (2007) Theoretical and developmental issues in the syntax of subjects: Evidence from near-native Italian. Natural Language \& Linguistic Theory, 25(4), pp. 657-689.

Bini, M. (1993) La adquisicíon del italiano: Mas allá de las propiedades sintácticas del parámetro pro-drop. In J. Liceras (Ed.), La linguistica y el analisis de los sistemas no nativos. Ottawa: Doverhouse, pp. 126-139.

Birner, B. (1994) Information status and word order: An analysis of English inversion. Language, 70(2), pp. 233-259.

Birner, B. (1996) The discourse function of inversion in English. Nova Iorque / Londres: Routledge.

Birner, B. \& G. Ward (1998) Information status and noncanonical word order in English. Amesterdão: John Benjamins.

Bohnacker, U. \& C. Rosén (2007) Transferring information-structural patterns from Swedish to German. In A. Belikova, L. Meroni, \& M. Umeda (Eds.), Proceedings of Generative Approaches to Language Acquisition North America 2. Somerville, MA Cascadilla Proceedings Project.

Branigan, H. P. (2007) Syntactic priming. Language and Linguistics Compass, 1(2), pp. 1-16.

Bresnan, J. (1994) Locative inversion and the architecture of Universal Grammar. Language, 70(1), pp. 72-131.

Chamorro, G., Sorace, A. \& Sturt, P. (2016) What is the source of L1 attrition? The effect of recent L1 re-exposure on Spanish speakers under L1 attrition. Bilingualism: Language and Cognition, 19(3), pp. 520-532.

Cornish, F. (2001) L’inversion "locative” en français, italien et anglais: Propriétés syntaxiques, sémantiques et discursives. Cahiers de Grammaire, 26, pp. 101-123.

Cornish, F. (2005) A cross-linguistic study of so-called "locative inversion": Evidence for the Functional Discourse Grammar model. In C. d. Groot \& K. Hengeveld (Eds.), Morphosyntactic expression in Functional Grammar. Berlin / Nova Iorque: Mouton de Gruyter, pp. 163-202. 
Culicover, P. W. \& R. D. Levine (2001) Stylistic inversion in English: A reconsideration. Natural Language \& Linguistic Theory, 19(2), pp. 283-310.

Culicover, P. W. \& S. Winkler (2008) English focus inversion. Journal of Linguistics, 44(03), pp. 625-658.

Cunnings, I. (2012) An overview of mixed-effects statistical models for second language researchers. Second Language Research, 28(3), pp. 369-382.

Domínguez, L. \& M. J. Arche (2014) Subject inversion in non-native Spanish. Lingua, 145, pp. 243-265.

Donaldson, B. (2011a) Left dislocation in near-native French Studies in Second Language Acquisition, 33(03), pp. 399-432.

Donaldson, B. (2011b) Nativelike right-dislocation in near-native French. Second Language Research, 27(3), pp. 361-390.

Holler, S. \& J. Hartmann (2012) Locative inversion in English: Implications of a rating study. In S. Featherston \& B. Stolterfoht (Eds.), Empirical approaches to linguistic theory: Studies in meaning and structure. Berlin: Mouton de Gruyter, pp. 241-265.

Hopp, H. (2004) Syntactic and interface knowledge in advanced and near-native grammars. In S. Foster-Cohen, M. S. Smith, A. Sorace \& M. Ota (Eds.), EuroSLA Yearbook 4. Amesterdão: John Benjamins, pp. 67-94.

Hopp, H. (2007) Ultimate attainment at the interfaces in second language acquisition: Grammar and processing. Dissertação de doutoramento, University of Groningen, Netherlands.

Ivanov, I. P. (2009) Topicality and clitic doubling in L2 Bulgarian: A test case for the Interface Hypothesis. In M. Bowles, T. Ionin, S. Montrul \& A. Tremblay (Eds.), Proceedings of the 10th Generative Approaches to Second Language Acquisition Conference (GASLA 2009). Somerville, MA: Cascadilla Press, pp. 17-24.

Ivanov, I. P. (2012) L2 acquisition of Bulgarian clitic doubling: A test case for the Interface Hypothesis. Second Language Research, 28(3), pp. 345-368.

Lahousse, K. (2003) The distribution of postverbal nominal subjects in French. A syntactic, semantic and pragmatic analysis. Dissertação de doutoramento, Université de Louvain \& Université Paris 8, Louvain / Paris. 
Lahousse, K. (2011) Quand passent les cigognes. Le sujet nominal postverbal en français contemporain. Paris: Presses Universitaires Vincennes.

Levin, B. (1993) English verb classes and alternations: A preliminary investigation. Chicago / Londres: The Chicago University Press.

Levin, B. \& M. Rappaport Hovav (1995) Unaccusativity at the syntax-lexical semantics interface. Cambridge, MA: MIT Press.

Linck, J. \& I. Cunnings (2015) The utility and application of mixed-effects models in second language research. Language Learning, 65, pp. 185-207.

Loewen, S. \& Plonsky, L. (2016) An A-Z of applied linguistics research methods. Londres: Palgrave.

Lozano, C. (2003) Universal Grammar and Focus constraints: the acquisition of pronouns and word order in non-native Spanish. Dissertação de doutoramento, University of Essex, UK.

Lozano, C. (2006a) The development of the syntax-discourse interface: Greek learners of Spanish. In V. Torrens \& L. Escobar (Eds.), The Acquisition of Syntax in Romance Languages. Amesterdão: John Benjamins.

Lozano, C. (2006b) Focus and split-intransitivity: the acquisition of word order alternations in non-native Spanish. Second Language Research, 22(2), pp. 145-187.

Lozano, C. (2008) Variability and optionality in second language grammars: A quantitative approach. In A. Linde López, J. Santana Lario \& C. Wallhead Salway (Eds.), Studies in honour of Neil McLaren: A man for all seasons. Granada: Editorial Universidad de Granada, pp. 59-75.

Madeira, A., M. F. Xavier \& M. L. Crispim (2009) A aquisição de sujeitos nulos em português L2 Estudos da Língua(gem) / Estudos em Aquisição de L1 e L2, 7(2), pp. 163-198.

Malgaza, P. \& A. Bel (2006) Null subjects at the syntax-pragmatics interface: Evidence from Spanish interlanguage of Greek speakers. In M. G. O’Brien, C. Shea \& J. Archibald (Eds.), Proceedings of GASLA 2006. Somerville, MA: Cascadilla Press, pp. 88-97.

Meisel, J. M. (2008) Child second language acquisition or successive first language acquisition? In B. Haznedar \& E. Gavruseva (Eds.), Current trends in child second language acquisition: A generative perspective. Amesterdão / Filadélfia: John Benjamins, pp. 5580. 
Mendes, C. \& I. C. Iribarren (2007) Fixação do parâmetro do sujeito nulo na aquisição do português europeu por hispanofalantes. In M. Lobo \& M. A. Coutinho (Eds.), Textos seleccionados do XXII Encontro Nacional da Associação Portuguesa de Linguística. Lisboa: Associação Portuguesa de Linguística, pp. 483-498.

Mendikoetxea, A. (2006) Unergatives that 'become' unaccusatives in English locative inversion: A lexical-syntactic approach. In C. Copy \& L. Gournay (Eds.), Points de vue sur l'inversion. Cahiers de recherche en grammaire anglaise de l'énonciation. Paris: Éditions Orphys, pp. 133-155.

Pereira, C. (1998) Inversão locativa em português. Dissertação de mestrado, Universidade do Porto, Porto.

Pickering, M. J. \& V. S. Ferreira (2008) Structural priming: A critical review. Psychological Bulletin, 134(3), pp. 427-459.

Rizzi, L. \& U. Shlonsky (2006) Satisfying the subject criterion by a non subject: English locative inversion and heavy NP shift. In M. Frascarelli (Ed.), Phases of interpretation. Berlin / Nova Iorque: Mouton de Gruyter, pp. 341-362.

Schütter, J. S. (2013) An investigation into near-nativeness at the syntax-lexicon interface: Evidence from Dutch learners of English. Dissertação de doutoramento, University of Edinburgh.

Slabakova, R. (2015) The effect of construction frequency and native transfer on second language knowledge of the syntax-discourse interface. Applied Psycholinguistics, 36(03), pp. 671-699.

Slabakova, R., P. Kempchinsky \& J. Rothman (2012) Clitic-doubled left dislocation and focus fronting in L2 Spanish: A case of successful acquisition at the syntax-discourse interface. Second Language Research, 28(3), pp. 319-343.

Slabakova, R., J. Rothman \& P. Kempchinsky (2011) Gradient competence at the syntaxdiscourse interface. In L. Roberts, G. Pallotti \& C. Bettoni (Eds.), EuroSLA Yearbook 11. Amesterdão: John Benjamins, pp. 218-243.

Slabakova, R., J. Rothman, T. Leal Mendez, G. Campos \& P. Kempchinsky (2011) Pragmatic features at the L2 syntax-discourse interface. In N. Danis, K. Mesh \& H. Sung (Eds.), BUCLD 35: Proceedings of the 35th annual Boston University Conference on Language Development. Sommerville, MA: Cascadilla Press, pp. 564-576. 
Sorace, A. (2003) Near-nativeness. In C. J. Doughty \& M. Long (Eds.), The handbook of second language acquisition. Oxford: Blackwell, pp. 130-151.

Sorace, A. (2011) Pinning down the concept of 'interface' in bilingualism. Linguistic Approaches to Bilingualism, 1, pp. 1-33.

Sorace, A. (2016) Referring expressions and executive functions in bilingualism. Linguistic Approaches to Bilingualism, 6(5), pp. 669-684.

Sorace, A. \& F. Filiaci (2006) Anaphora resolution in near-native speakers of Italian. Second Language Research, 22(3), pp. 339-368.

Sorace, A., L. Serratrice, F. Filiaci \& M. Baldo (2009) Discourse conditions on subject pronoun realization: Testing the linguistic intuitions of older bilingual children. Lingua, 119(3), pp. $460-477$.

Teixeira, J. (2016a). From a Romance null subject grammar to a non-null subject grammar: The syntax of subjects in advanced and near-native English. Trabalho apresentado no Going Romance 30, Frankfurt.

Teixeira, J. (2016b) Inversão locativa e tópicos cénicos: Os casos do inglês, francês e português europeu. Revista da Associação Portuguesa de Linguística, 2, pp. 425-457.

Teixeira, J. (2016c) Locative inversion and stage topics: A cross-linguistic study. Discours 19, pp.5-28. URL: http://discours.revues.org/9229.

Tsimpli, I. \& A. Sorace (2006) Differentiating interfaces: L2 performance in syntax-semantics and syntax-discourse phenomena Proceedings of the 30th Annual Boston University Conference on Language Development. Somerville, MA: Cascadilla Press, pp. 653-664.

Tsimpli, I., Sorace, A., Heycock, C. \& Filiaci, F. (2004) First language attrition and syntactic subjects: A study of Greek and Italian near-native speakers of English. International Journal of Bilingualism, 8(3), pp. 257-277.

Ward, G., B. Birner \& R. Huddleston (2002) Information packaging. In R. Huddleston \& G. K. Pullum (Eds.), The Cambridge grammar of the English language. Cambridge: Cambridge University Press, pp. 1363-1447.

White, L. \& F. Genesee (1996) How native is near-native? The issue of ultimate attainment in adult second language acquisition. Second Language Research, 12(3), pp. 233-265. 
White, L. (2009) Grammatical theory: Interfaces and L2 knowledge. In W. C. Ritchie \& T. K. Bhatia (Eds.), The new handbook of second language acquisition. Leeds: Emerald, pp.49-68.

White, L. (2011) Second language acquisition at the interfaces. Lingua, 121(4), pp. 577-590.

Wilson, F. (2009) Processing at the syntax-discourse interface in second language acquisition. Dissertação de doutoramento, University of Edinburgh, Edimburgo.

Wilson, F., A. Sorace \& F. Keller (2009) Antecedent preferences for anaphoric demonstratives in L2 German. In J. Chandlee, M. Franchini, S. Lord \& G.-M. Rheiner (Eds.), BUCLD 33: Proceedings of the 33rd annual Boston University Conference on Language Development. Sommerville, MA: Cascadilla Press, pp. 634-645. 